OPEN ACCESS

Edited by:

Ewa Teresa Marcinkowska, University of Wroctaw, Poland

Reviewed by: Katharina F. Witting,

Leiden University Medical Center,

Netherlands

Wei-Ling Tsou,

Wayne State University, United States

${ }^{*}$ Correspondence:

Feng Wang

wfeng@bit.edu.cn

Specialty section:

This article was submitted to

Experimental Pharmacology and Drug

Discovery,

a section of the journa

Frontiers in Pharmacology

Received: 24 March 2021

Accepted: 25 May 2021

Published: 10 June 2021

Citation:

Wang $Y$ and Wang $F$ (2021) Post-

Translational Modifications of

Deubiquitinating Enzymes: Expanding

the Ubiquitin Code.

Front. Pharmacol. 12:685011.

doi: 10.3389/fphar.2021.685011

\section{Post-Translational Modifications of Deubiquitinating Enzymes: Expanding the Ubiquitin Code}

\author{
Yanfeng Wang and Feng Wang * \\ Key Laboratory of Molecular Medicine and Biotherapy, School of Life Science, Beijing Institute of Technology, Beijing, China
}

Post-translational modifications such as ubiquitination play important regulatory roles in several biological processes in eukaryotes. This process could be reversed by deubiquitinating enzymes (DUBs), which remove conjugated ubiquitin molecules from target substrates. Owing to their role as essential enzymes in regulating all ubiquitin-related processes, the abundance, localization, and catalytic activity of DUBs are tightly regulated. Dysregulation of DUBs can cause dramatic physiological consequences and a variety of disorders such as cancer, and neurodegenerative and inflammatory diseases. Multiple factors, such as transcription and translation of associated genes, and the presence of accessory domains, binding proteins, and inhibitors have been implicated in several aspects of DUB regulation. Beyond this level of regulation, emerging studies show that the function of DUBs can be regulated by a variety of post-translational modifications, which significantly affect the abundance, localization, and catalytic activity of DUBs. The most extensively studied post-translational modification of DUBs is phosphorylation. Besides phosphorylation, ubiquitination, SUMOylation, acetylation, oxidation, and hydroxylation are also reported in DUBs. In this review, we summarize the current knowledge on the regulatory effects of post-translational modifications of DUBs.

Keywords: DUBs, post-translational modifications, phosphorylation, ubiquitination, sumoylation, acetylation, oxidation, hydroxylation

\section{INTRODUCTION}

Ubiquitination is an essential post-translational protein modification mediated by the ubiquitin (Ub)-conjugating system, which is composed of a Ub-activating enzyme, E1, Ub-conjugating enzyme, E2, and Ub ligase, E3 (Hershko and Ciechanover, 1998). The human genome encodes more than 600 E3 ligases. The E2 enzyme is specific for this type of ligation and co-ordinately functions with multiple E3 ligases. Thus, the series of enzyme combinations determine the diversity of the ubiquitination process. Therefore, ubiquitination drives diverse biological signals that regulate the fate and function of a plethora of intracellular proteins (Reyes-Turcu et al., 2009).

Ubiquitination is a reversible process because the conjugated $\mathrm{Ub}$ molecule can be trimmed away from the target protein by deubiquitination enzymes (DUBs). The human genome encodes several kinds of DUBs, which can be divided into seven subfamilies (Nijman et al., 2005). Among these, six subfamilies include Ub-specific proteases (USPs), Ub C-terminal hydrolases (UCHs), ovarian tumour proteases (OTUs), Machado-Josephin domain-containing proteases (MJDs), MIUcontaining novel DUB (MINDY), and zinc finger-containing ubiquitin peptidase 1 (ZUP1) 
(cysteine-dependent proteases). In contrast, the seventh family, Jab1/MPN domain-associated metallopeptidase (JAMM/MPN+), comprises of zinc-dependent metalloproteinases (Mizuno et al., 2007; Mevissen and Komander, 2017).

The human genome encodes a relatively small number of DUBs compared to Ub ligases; multiplicity does not seem to exist in DUBs. However, a large amount of regulatory mechanisms precisely expand the functions of DUBs in various Ub-related processes to ensure accurate biological responses (Sahtoe and Sixma, 2015). The regulatory mechanisms of DUBs can be globally classified into post-translational modifications (PTMs), substrate-induced changes, scaffold or binding protein-induced changes (Cannavo et al., 2007; Hsu et al., 2017), and inhibitorinduced changes (Nijman et al., 2005; Sahtoe and Sixma, 2015). The regulation of DUBs mainly involves control of catalytic activity, abundance, and localization of DUBs. Dysregulation of DUBs can cause a variety of disorders, such as cancer, and neurodegenerative and inflammatory diseases (Todi and Paulson, 2011; Lopez-Castejon and Edelmann, 2016; Pinto-Fernandez and Kessler, 2016).

With the advancement of analytical tools such as mass spectrometry, PTM sites of DUBs have been identified. Recently, the regulation of DUBs by PTMs and its physiological relevance have been revealed. Studies showed that PTMs can regulate the function of DUBs by altering factors such as its stability, localization, abundance, and catalytic activity, in addition to its involvement in the cell signalling pathway (Kessler and Edelmann, 2011). Here, we will review the regulatory effects of PTMs on DUBs, and its potential therapeutic role in tumour growth (Table 1). PTMs mainly consist of phosphorylation, ubiquitination, SUMOylation, acetylation, oxidation and hydroxylation, all of which have critical roles in the regulation of DUBs (Figure 1). Analysis of these regulatory processes may provide evidence for elucidating the function of DUBs and their potential as targets in novel therapeutic strategies.

\section{PTMS REGULATE THE ABUNDANCE OF DUBS}

The most straightforward mechanism affecting the biological function of a given protein is its intracellular concentration. Like other signalling proteins, this fact is also applicable to DUBs. The quantity of DUBs is cell or tissue-specific; UCHs subfamily of DUBs are highly abundant in neurons (Liu et al., 2009). In contrast, DUBs such as USP30 show relatively low expression levels in neurons. Therefore, this highlights the specific spatial and temporal functional of DUBs in different cells or tissues (Clague et al., 2015). In addition, the abundance of DUBs is strictly controlled by regulation of its transcription, translation, PTMs, and degradation. In the following sections, we summarize how PTMs such as phosphorylation and ubiquitination regulate the abundance of DUBs (Das et al., 2020).

\section{Regulation of DUB Stability and Abundance by Phosphorylation}

Phosphorylation is an important kind of PTM that influences the essential physiological role of DUBs, and exerts its effect by elevating, stabilizing, or reducing its abundance. Phosphorylation can elevate DUB protein levels by altering their self-assembly and interaction with other partners. Results have shown that AKT-mediated phosphorylation of USP4 at the Ser445 residue is essential for it to form a complex with itself or with other protein partners, such as USP15 or T $\beta$ RI (Zhang et al., 2012). In particular, when USP4 was co-expressed with USP15, an elevated USP4 protein level was detected. Additionally, AKTinduced phosphorylation of USP4 is required for maintaining the stability of USP4, thereby enhancing TGF- $\beta$-induced protumorigenic responses in breast cancer cells. TGF- $\beta$-induced migration of MDA-MB-231 cells is inhibited by USP4 knockdown and PI (3) K-AKT signalling inhibitors, indicating that phosphorylation of USP4 plays a critical role in AKTmediated breast cancer cell migration (Zhang et al., 2014; Wang W. et al., 2020). Therefore, phosphorylation is essential for stabilizing and maintaining the protein levels of USP4 and plays a potential role in breast cancer pathogenesis (Zhang et al., 2012).

Furthermore, protein kinase CK2-induced phosphorylation of USP7 at the Ser18 residue plays a major role in maintaining the stability of USP7 protein (Khoronenkova et al., 2012). Phosphorylation can prevent the ubiquitination of USP7 and prevent its degradation by the proteasome. The dephosphorylation of USP7 decreased its stability and makes it prone to proteasomal degradation. Generally, large amounts of USP7 are phosphorylated by CK2 and remain active in unstressed cells (Olsten and Litchfield, 2004). This promotes the deubiquitination and stabilization of $\mathrm{Mdm} 2$, which in turn leads to the degradation and downregulation of p53. However, when DNA damage occurs, USP7 is dephosphorylated by PPM1G, which induces p53 stabilization due to $\mathrm{Mdm} 2$ degradation, which suggests that inhibition of the phosphorylation of USP7, as a part of the DNA damage response (DDR), may exhibit a potential therapeutic effect (Fernández-Montalván et al., 2007; Khoronenkova et al., 2012; Pozhidaeva and Bezsonova, 2019).

On the contrary, phosphorylation can also reduce DUB protein levels by altering the degradation pathway of DUBs. For instance, SYK-dependent phosphorylation of USP25 at residue Tyr740 can sharply reduce its protein levels. This is not caused by proteasome-dependent degradation because addition of a proteasome inhibitor did not rescue USP25 proteins levels (Figure 3A). Therefore, it is reasonable to assume that SYK-dependent phosphorylation may activate other pathways, such as lysosomal degradation, to alter USP25 protein levels (Cholay et al., 2010; Kim et al., 2015).

\section{Ubiquitination Induces the Auto-Deubiquitination of DUBs}

Ubiquitination and deubiquitination are two types of important PTMs. Usually, DUBs play a critical role in the Ub proteasome system (UPS) by deubiquitinating the protein substrate (Komander et al., 2009). Interestingly, DUB can also be ubiquitinated itself to alter its destiny either by promoting or decreasing its degradation. For example, many DUBs undergo 
TABLE 1 | Summary of DUBs localization, PTMs and interaction profile.

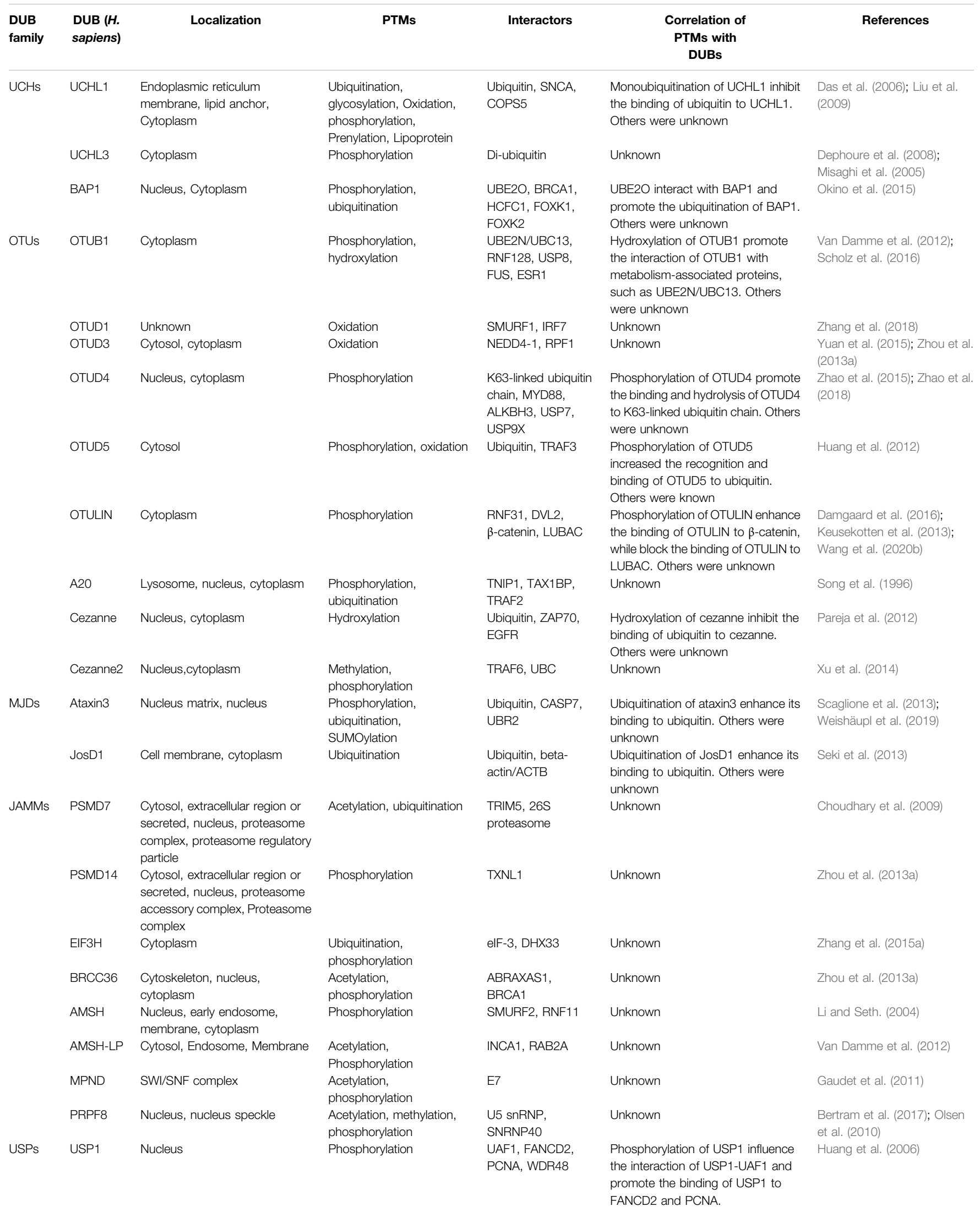


TABLE 1 | (Continued) Summary of DUBs localization, PTMs and interaction profile.

\begin{tabular}{|c|c|c|c|c|c|c|}
\hline $\begin{array}{l}\text { DUB } \\
\text { family }\end{array}$ & $\begin{array}{l}\text { DUB }(H . \\
\text { sapiens) }\end{array}$ & Localization & PTMs & Interactors & $\begin{array}{l}\text { Correlation of } \\
\text { PTMs with } \\
\text { DUBs }\end{array}$ & References \\
\hline & USP4 & Nucleus, cytoplasm & $\begin{array}{l}\text { Phosphorylation, } \\
\text { ubiquitination }\end{array}$ & $\begin{array}{l}\text { CtIP/MRN, } \\
\text { ADORA2A, RB1, } \\
\text { USP15 or T } \beta \text { RI }\end{array}$ & $\begin{array}{l}\text { Phosphorylation of USP4 promote } \\
\text { its binding to USP } 15 \text { and T } \beta \text { RI. Auto- } \\
\text { deubiquitination of USP4 is required } \\
\text { for USP4 to interact with CtIP/MRN. }\end{array}$ & $\begin{array}{l}\text { Uras et al. (2012); Wijnhoven } \\
\text { et al. (2015) }\end{array}$ \\
\hline & USP6 & $\begin{array}{l}\text { Cell membrane, endosome, } \\
\text { cytoplasm }\end{array}$ & Ubiquitination & $\begin{array}{l}\mathrm{Ca}^{2+} / \text { Calmodulin, } \\
\mathrm{RAC} 1, \mathrm{CDC} 42\end{array}$ & $\begin{array}{l}\text { Ubiquitination of USP6 promote its } \\
\text { binding to } \mathrm{Ca}^{2+} / \text { Calmodulin. Others } \\
\text { were unknown }\end{array}$ & Shen et al. (2005a) \\
\hline & USP7 & $\begin{array}{l}\text { Nucleus, PML body, cytoplasm, } \\
\text { chromosome }\end{array}$ & $\begin{array}{l}\text { Phosphorylation, oxidation, } \\
\text { ubiquitination }\end{array}$ & FOXO4, MDM2 & $\begin{array}{l}\text { Phosphorylation of USP7 promote } \\
\text { the stabilization of MDM2 through } \\
\text { deubiquitinating it }\end{array}$ & $\begin{array}{l}\text { Fernández-Montalván et al. } \\
\text { (2007) }\end{array}$ \\
\hline & USP8 & $\begin{array}{l}\text { Nucleus, endosome membrane, } \\
\text { membrane protein, cell } \\
\text { membrane, peripheral } \\
\text { membrane protein, cytoplasm }\end{array}$ & Phosphorylation & $\begin{array}{l}\text { 14-3-3 protein, } \\
\text { LC3, STAM2 }\end{array}$ & $\begin{array}{l}\text { Phosphorylation of USP8 promote } \\
\text { its binding to } 14-3-3 \text { protein. Others } \\
\text { were unknown }\end{array}$ & $\begin{array}{l}\text { Dephoure et al. (2008); Row } \\
\text { et al. (2009) }\end{array}$ \\
\hline & USP9X & Cytoplasm, growth cone & Phosphorylation & $\begin{array}{l}\text { ZAP70, } \\
\text { SMAD4, DCX }\end{array}$ & $\begin{array}{l}\text { Phosphorylation of USP9X promote } \\
\text { the deuibiquitination of ZAP70. } \\
\text { Others were unknown }\end{array}$ & $\begin{array}{l}\text { Homan et al. (2014); Zhou } \\
\text { et al. (2013b) }\end{array}$ \\
\hline & USP10 & $\begin{array}{l}\text { Early endosome, Nucleus, } \\
\text { cytoplasm }\end{array}$ & Phosphorylation & TRF6, p53, AMPK & $\begin{array}{l}\text { Phosphorylation of USP10 promote } \\
\text { the deuibiquitination and stabilization } \\
\text { of p53 and AMPK. }\end{array}$ & $\begin{array}{l}\text { Wang et al. (2015a); Yuan } \\
\text { et al. (2010) }\end{array}$ \\
\hline & USP11 & $\begin{array}{l}\text { Nucleus, cytoplasm, } \\
\text { chromosome }\end{array}$ & Ubiquitination & NFKBIA, BRCA2 & Unknown & $\begin{array}{l}\text { Schoenfeld et al. (2004); } \\
\text { Wiltshire et al. (2010) }\end{array}$ \\
\hline & USP13 & Cytosol, nucleoplasm & Phosphorylation & $\begin{array}{l}\text { Aurora B, RAP80, } \\
\text { c-Myc, SIAH2, } \\
\text { BAG6 }\end{array}$ & $\begin{array}{l}\text { Phosphorylation of USP13 promote } \\
\text { its interaction with aurora B, RAP80, } \\
\text { and C-Myc. Others were unknown }\end{array}$ & $\begin{array}{l}\text { Esposito et al. (2020); } \\
\text { Scortegagna et al. (2011); } \\
\text { Zhou et al. (2020) }\end{array}$ \\
\hline & USP14 & $\begin{array}{l}\text { Cell membrane, peripheral } \\
\text { membrane protein, cytoplasm }\end{array}$ & Phosphorylation & $\begin{array}{l}\text { Ubiquitin, CXCR4, } \\
\text { fANCC }\end{array}$ & $\begin{array}{l}\text { Phosphorylation of USP14 promote } \\
\text { its binding to ubiquitin. Others were } \\
\text { unknown }\end{array}$ & $\begin{array}{l}\text { Mines et al. (2009); Zhou et al. } \\
\text { (2013a) }\end{array}$ \\
\hline & USP15 & $\begin{array}{l}\text { Nucleus, mitochondrion, } \\
\text { cytoplasm }\end{array}$ & $\begin{array}{l}\text { Phosphorylation, } \\
\text { ubiquitination }\end{array}$ & SMAD1, SMAD2 & $\begin{array}{l}\text { Auto-deubiquitination of USP15 } \\
\text { promote its interaction with SMAD1 }\end{array}$ & $\begin{array}{l}\text { Cornelissen et al. (2014); Inui } \\
\text { et al. (2011) }\end{array}$ \\
\hline & USP19 & $\begin{array}{l}\text { Endoplasmic reticulum } \\
\text { membrane, single-pass } \\
\text { membrane protein }\end{array}$ & Oxidation & $\begin{array}{l}\text { C-IAP1, c-IAP2, } \\
\text { RNF123 }\end{array}$ & Unknown & Mei et al. (2011) \\
\hline & USP25 & Cytoplasm, nucleus, cytoplasm & $\begin{array}{l}\text { Phosphorylation, } \\
\text { ubiquitination, } \\
\text { SUMOylation }\end{array}$ & $\begin{array}{l}\text { SYK, Sumo1, } \\
\text { Sumo2, TRiC, ub } \\
\text { chains }\end{array}$ & $\begin{array}{l}\text { SYK-dependent phosphorylation of } \\
\text { USP25 promote the stabilization of } \\
\text { TRiC, SUMOylation of USP25 inhibit } \\
\text { its binding to ub chains }\end{array}$ & $\begin{array}{l}\text { Cholay et al. (2010); Denuc } \\
\text { et al. (2009) }\end{array}$ \\
\hline & USP28 & Nucleoplasm & SUMOylation, oxidation & ZNF304, Fbw7 & Unknown & $\begin{array}{l}\text { Popov et al. (2007a); Popov } \\
\text { et al. (2007b); Zhang et al. } \\
\text { (2006) }\end{array}$ \\
\hline & USP30 & Mitochondrion outer membrane & Ubiquitination & EAP1, POMK & Unknown & $\begin{array}{l}\text { Bingol et al. (2014); Huttlin } \\
\text { et al. (2017) }\end{array}$ \\
\hline & USP36 & Nucleolus, cytoplasm & Phosphorylation & C-myc, NEDD4L & Unknown & Sun et al. (2015) \\
\hline & USP37 & Nucleoplasm, nucleus & Phosphorylation & $\mathrm{FZR} 1 / \mathrm{CDH} 1, \mathrm{CDT} 1$ & $\begin{array}{l}\text { Phosphorylation of USP37 enhance } \\
\text { its binding to the substrate adaptor } \\
\text { CDH1. Others were unknown }\end{array}$ & Huang et al. (2011) \\
\hline & USP39 & Unknown & SUMOylation & Tri-snRNP, LRRK2 & $\begin{array}{l}\text { SUMOylation of USP39 promote its } \\
\text { interaction with tri-snRNP. }\end{array}$ & Liu et al. (2015a) \\
\hline & USP44 & Nucleus & $\begin{array}{l}\text { Phosphorylation, } \\
\text { ubiquitination }\end{array}$ & CETN2, EZH2 & Unknown & $\begin{array}{l}\text { Lan et al. (2016); Suresh et al. } \\
\text { (2010); Visconti et al. (2012) }\end{array}$ \\
\hline & USP47 & Cytoplasm & $\begin{array}{l}\text { Acetylation, } \\
\text { phosphorylation }\end{array}$ & $\begin{array}{l}\text { BTRC, FBXW11, } \\
\text { POLB }\end{array}$ & Unknown & $\begin{array}{l}\text { Parsons et al. (2011); } \\
\text { Peschiaroli et al. (2010) }\end{array}$ \\
\hline & USP49 & Nucleus & Phosphorylation & RUVBL1, PSMC5 & Unknown & Zhang et al. (2013) \\
\hline & CYLD & $\begin{array}{l}\text { Cytoskeleton, centrosome, } \\
\text { spindle cilium basal body, } \\
\text { plasma membrane, cytoplasm } \\
\text { perinuclear region }\end{array}$ & $\begin{array}{l}\text { Phosphorylation, } \\
\text { SUMOylation, oxidation }\end{array}$ & $\begin{array}{l}\text { TRAF2, SPATA2, } \\
\text { MAP3K7 }\end{array}$ & $\begin{array}{l}\text { Phosphorylation or SUMOylation of } \\
\text { CYLD inhibit its interaction of TRAF2. } \\
\text { Others were unknown }\end{array}$ & $\begin{array}{l}\text { Eguether et al. (2014); ji et al. } \\
\text { (2018); Schlicher et al. (2016) }\end{array}$ \\
\hline & USPL1 & Cajal body & Phosphorylation & ELL & Unknown & $\begin{array}{l}\text { Hutten et al. (2014); Schulz } \\
\text { et al. (2012) }\end{array}$ \\
\hline
\end{tabular}


mono/poly-ubiquitination modification processes, and are then subjected to proteasomal degradation, resulting in a decrease in DUB protein levels (Wada et al., 2006). However, several DUBs have an auto-deubiquitination mechanism to prevent its degradation. Studies have shown that USP4 is a stable DUB protein because it can deubiquitinate itself after being ubiquitinated by Ro52 (Wada and Kamitani, 2006; Zhang et al., 2012). Similar to that of USP4, the self-deubiquitination of USP25 confers a protection mechanism to prevent it from proteasomal degradation (Figure 3A) (Denuc et al., 2009).

\section{PTMS CAN REGULATE THE LOCALIZATION OF DUBS}

The subcellular localization of DUBs is also a key factor in determining the function of DUBs (Clague et al., 2015). If both the enzyme and the substrate circulate freely, they will be diluted in the cytoplasm or separated into different subcellular organelles, which will not allow the enzyme-catalysed reaction to occur at an appropriate enzymatic rate. Currently, the localization

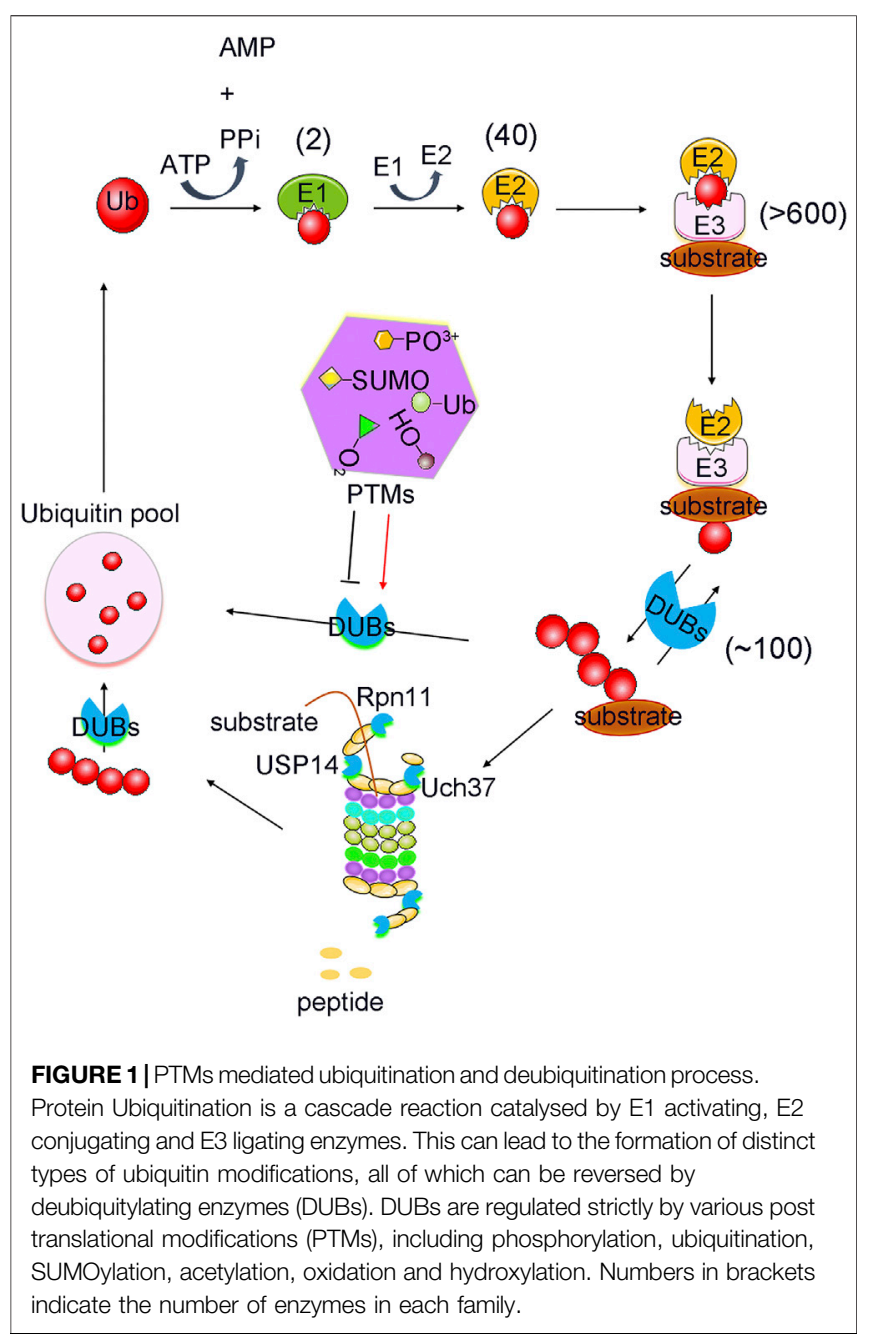

of DUBs is garnering attention as a vital regulatory mechanism (Mevissen and Komander, 2017).

Indeed, the subcellular localization of some DUBs is tightly controlled so as to facilitate its biological functions. In previous studies involving systematic large-scale proteomic analyses, the subcellular distribution of GFP-labelled DUBs was analysed in HeLa cell lines (Urbé et al., 2012) (Figure 2A). DUBs such as USP1, USP7, and USP11 were located in the nucleus, whereas other DUBs were localized in specific cellular compartments. Briefly, approximately nineteen DUBs were localized in the endoplasmic reticulum, twelve in the endosomes, eight in the mitochondria, and fifteen in the plasma membrane (Urbé et al., 2012; Clague et al., 2015). It is precisely because of these diverse localizations that the unique biological functions of DUBs are inferred. For example, the localization of USP36 in the nucleus allows it to specifically interact with the transcription factor c-Myc and deubiquitylate it (Sun et al., 2015). In the same way, USP30 located in the outer mitochondrial membrane can regulate mitochondrial morphology and plays a critical role in Parkin-mediated mitophagy (Nakamura and Hirose, 2008). Moreover, in lung cancer cells, the nucleus-localized USP15 can deubiquitylate histone $\mathrm{H} 2 \mathrm{~B}$ and inhibit degradation of the RE1silencing transcription factor (REST) on the ribosome, which plays a pivotal role in cell cycle oscillations (Faronato et al., 2013).

More interestingly, recent studies have shown that the localization of DUBs in cells can be dynamically regulated to facilitate their complex biological functions (Kessler and Edelmann, 2011; Leznicki and Kulathu, 2017; Mevissen and Komander, 2017; Das et al., 2020). For example, PTMs can regulate and alter the localization of DUBs in a variety of ways, including PTM-induced DUB translocation from the cytoplasm to the nucleus, PTM-induced excretion of DUBs from the nucleus, and PTM-induced DUB translocation to the cell membrane (Figure 2B). All of these factors contribute to the functional diversity and substrate specificity of DUBs.

\section{Phosphorylation Regulates the Interactome and Localization of DUBs}

Phosphorylation can also affect the function of various DUBs by altering its localization or interactome. Phosphorylation can cause some DUBs to be exported from the nucleus (Figure 2B). For instance, dephosphorylated USP4 accumulates in the nucleus, whereas the AKT-mediated phosphorylated form of USP4 (at residue Ser445) was primarily localized in the cytoplasm and cell membrane. The phosphorylation of USP4 prolongs its half-life on the plasma membrane, and activates TGF- $\beta$ cell signalling through binding and deubiquitination of TGF- $\beta$ receptors, which plays a crucial role in tumour cell migration and metastasis. This highlights the potential therapeutic role of USP4 phosphorylation in tumour progression (Zhang et al., 2012; Wang Y. et al., 2020). Recent studies have also shown the forms of USP15 phosphorylated at Thr149 and Thr219 residues are predominantly localized in the cytoplasm. In contrast, dephosphorylated USP15 relocates to the nucleus and plays an important role in spliceosome dynamics (Das et al., 2019). 


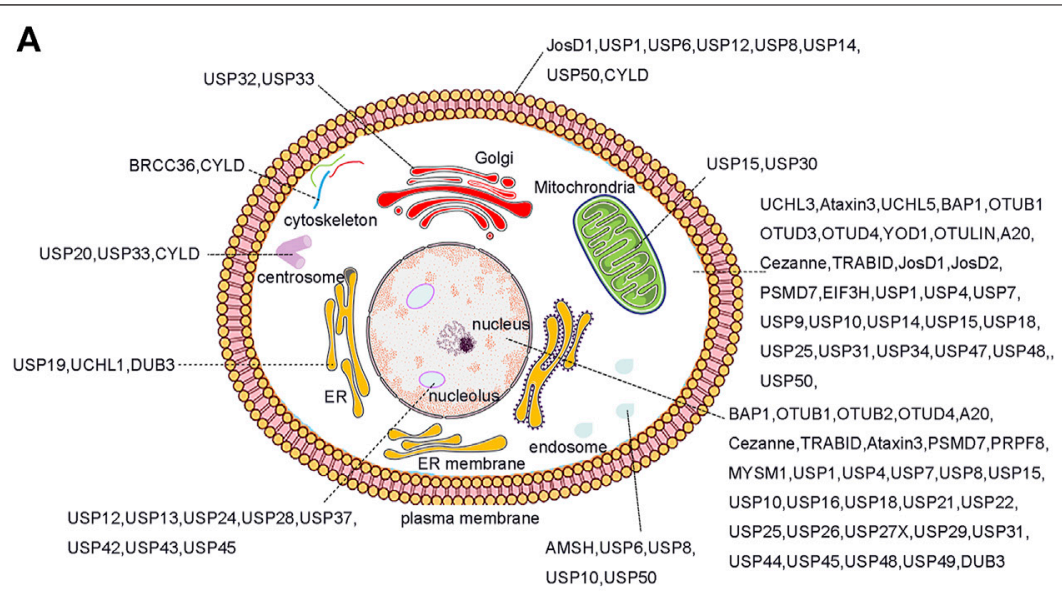

B
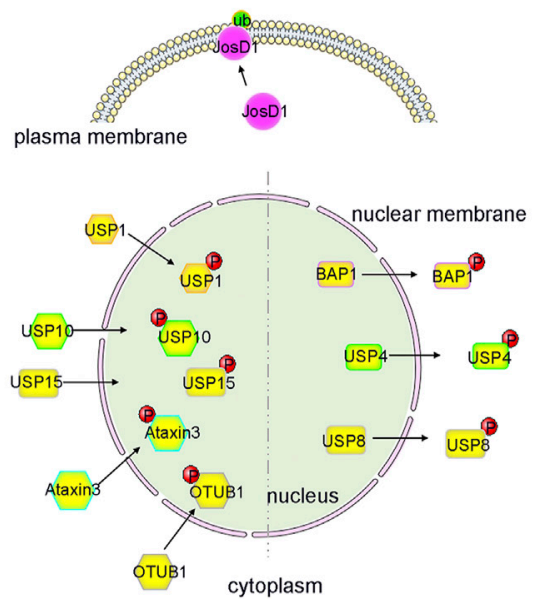

FIGURE 2 | Localization and PTMs induced translocation of DUBs. (A) DUBs have been reported to localize and function in almost every intracellular compartment, such as nucleolus, cell membrane and mitochrondria etc., and have specific roles. Importantly, the function of DUB can be expanded by ensuring that a single DUB localizes to distinct organelles as shown, for example, for JosD1, USP4 and USP25 etc. (B) PTMs, such as phosphorylation and ubiquitination, play an important role in regulation the alternative localization of DUB. For example, phosphorylation of BAP1, USP4 and USP8 causes them to relocate from the nucleus to the cytosol. In contrast, phosphorylation of OTUB1, Ataxin3, USP15, USP10, and USP1 triggers its translocation from cytosol to the nucleus. Additionally, ubiquitination of JosD1 leads its translocation from cytosol to cell membrane. The figure was generated based on the reported studies.

Furthermore, phosphorylation can induce the translocation of specific DUBs into the nucleus (Figure 2B). For example, after DNA damage, Ataxia telangiectasia mutated (ATM)induced phosphorylation of USP10 at residues Thr42 and Ser337 can promote the stability of USP10 and facilitate its translocation from the cytoplasm to the nucleus. Furthermore, phosphorylated USP10 can deubiquitinate and stabilize the tumour suppressor protein $\mathrm{p} 53$ by reversing its nuclear export and degradation via Mdm2. Therefore, phosphorylated USP10 can inhibit the growth of tumour cells without inducing mutations in $\mathrm{p} 53$, which implies that phosphorylation of USP10 has a potential therapeutic effect against tumours (Mueller et al., 2009; Yuan et al., 2010; Herhaus et al., 2015). Under oxidative stress, the phosphorylation of Ataxin3 at Ser111 is required for its nuclear localization (Costa and Paulson, 2012). Although progress has been made on the phosphorylation-induced localization changes of different DUBs, the understanding of the regulation mechanisms associated with PTMs, particularly in relation to DUB localization, is still limited.

Under certain conditions, phosphorylation-mediated changes in DUB localization can be observed by altering DUB interactions. Phosphorylation of USP1 on Ser313 can influence its interaction with the cofactor USP1-associated factor 1 (UAF1). The complex comprising of USP1 and UAF1 was localized in the cytoplasm. After phosphorylation of USP1, the complex translocated to the nucleus, where the recruitment of the Fanconi anemia protein FANCD2 and PCNA substrates mediated by a SUMO-like domain occurs in response to DNA damage (Huang et al., 2006; Garcia-Santisteban et al., 2012; Villamil et al., 2012; Olazabal-Herrero et al., 2015).

Similarly, DNA damage-induced ABL1/c-Abl (ABL protooncogene 1) activation can promote the phosphorylation of OTULIN at Tyr56, which enhances its interaction with $\beta$-catenin and blocks its binding to LUBAC (Keusekotten et al., 2013; Elliott et al., 2014; Schaeffer et al., 2014). Then, an increased OTULIN/ $\beta$-catenin interaction promotes the 


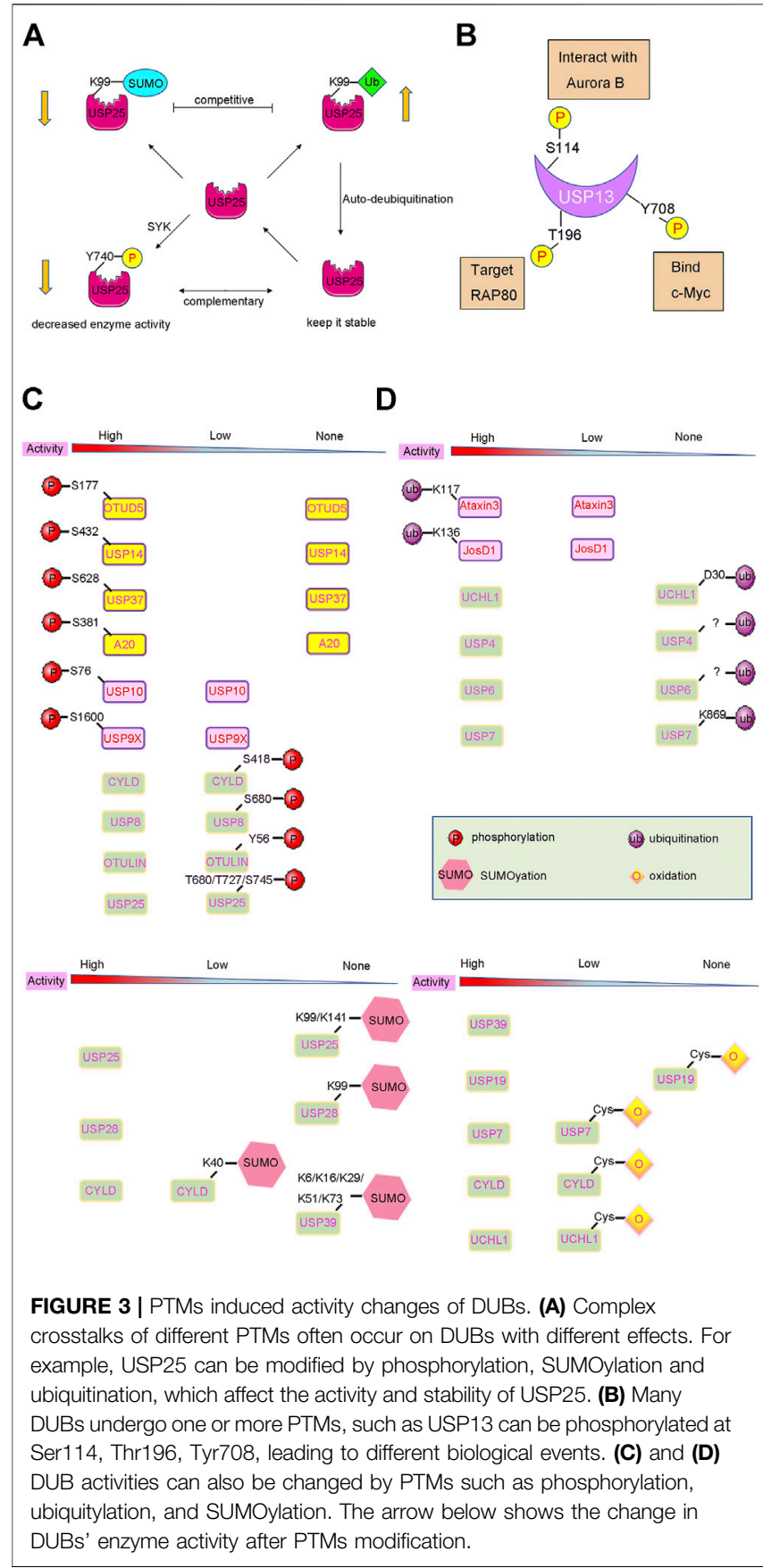

stabilization of $\beta$-catenin and activation of $\mathrm{Wnt} / \beta$-catenin signalling. This pathway plays a critical role in the progression and metastasis of triple-negative breast cancer (TNBC), metastasis, and resistance to cancer treatments. Therefore, targeting OTULIN or OTULIN phosphorylation may serve as an effective strategy for the treatment of patients with TNBC (Wang W. et al., 2020; Wang and Wu, 2020). Additionally, a study also reported that OTULIN is hyper-phosphorylated at Tyr56 residues during necroptosis, which can modulate ubiquitination of the receptor interacting protein kinase (RIPK1) and promote cell death (Douglas and Saleh, 2019).
Furthermore, the kinase Aurora B plays an important role in mitosis. The protein level of Aurora B varies during the course of cell division. The abnormal regulation of Aurora B during interphase leads to cell cycle defects, which are usually associated with aberrant chromosomal condensation and segregation (Gully et al., 2012). Studies have shown that Aurora B phosphorylates USP13 at Ser114 and promotes its interaction with USP13. USP13, in turn, deubiquitinates Aurora B to protect it from proteasomal degradation, thereby stabilizing the protein levels of Aurora B (Figure 3B). Therefore, this ensures proper regulation of Aurora $B$ and consequently the cell cycle, thereby preventing several human cancers, especially those cancers where Aurora B overexpression has been reported, such as ovarian, lung, brain, and skin-melanoma related cancers (Zeng et al., 2007; Chen et al., 2009; Esposito et al., 2020).

The receptor-associated protein 80 (RAP80) can recruit BRCA1 to DNA double-strand breaks and induce a DDR (Kim et al., 2007; Sobhian et al., 2007; Hu et al., 2011). Recent studies have reported that the deubiquitinating enzyme USP13 can regulate DDR by targeting RAP80. Mechanistically, USP13 is phosphorylated at Thr196 by ATM following DNA damage, which facilitates the localization of USP13 at the double-strand breaks. Then, USP13 can deubiquitinate RAP80 and stimulate its recruitment to induce an adequate DNA DDR (Figure 3B). Overall, USP13 functions as an essential regulator of DNA repair, and plays a vital role in the resistance of ovarian cancer cells to chemotherapy, and may provide a new approach for the treatment of ovarian cancer (Li et al., 2017).

Moreover, a recent study also found that CDC-like kinase 3 (CLK3) or the cholangiocarcinoma-associated CLK3-Q607R mutant can directly phosphorylate USP13 at Tyr708, and promote its binding to c-Myc (Nayler et al., 1997; Zhou et al., 2020) (Figure 3B). Therefore, this stabilizes c-Myc and activates the transcription of genes related to purine metabolism (Figure 3B). Thus, CLK3-mediated phosphorylation of USP13 at Tyr708 promotes cholangiocarcinoma progression by activating c-Myc-induced purine synthesis, providing a new and viable therapeutic target for the treatment of cholangiocarcinoma associated with CLK3 mutations (Zhou et al., 2020).

\section{Ubiquitylation Induces Changes in the Localization and Interactome of DUBs}

Ubiquitination plays an essential role in numerous cellular processes, such as protein degradation, cell cycle, and transcriptional regulation (Reyes-Turcu et al., 2009). Similar to protein phosphorylation, ubiquitination is a critical PTM occurring in DUBs, which can alter the localization of DUBs and regulate their physiological functions (Leznicki and Kulathu, 2017; Das et al., 2020).

Josephin domain containing 1 (JosD1), a DUB of the MJD subfamily, mainly associates with the cytoskeleton. However, when ubiquitination occurs on JosD1, it tends to localize on the cell membrane (Figure 2B) and plays a vital role in membrane dynamics, cell motility, and endocytosis (Seki et al., 2013; Zeng et al., 2020). 
Furthermore, BAP1, a member of the UCHs subfamily, is predominantly located in the nucleus and functions as a tumour suppressor (Cheung and Testa, 2017; Lee et al., 2020; Han et al., 2021). The lysine residues near the nuclear localization sequence (NLS) of BAP1 can be ubiquitinated, which leads to the accumulation of ubiquitinated BAP1 in the cytosol. Moreover, when BAP1 is co-expressed with UBE2O, it displays significant cytoplasmic staining. This is also due to the ubiquitination of BAP1 near the NLS by UBE2O. Studies have shown that the autodeubiquitination of BAP1 can counteract this process through intramolecular interactions, thereby ensuring its function in tumour suppression (Mashtalir et al., 2014; Okino et al., 2015).

Similar to phosphorylation of DUBs, ubiquitination can also change the localization of DUBs, which can be detected by changing the interaction partners of DUBs. However, autodeubiquitination, which is dependent on the catalytic activity of DUBs, can counteract the effect of ubiquitination modification and promote the interaction between DUB and its substrates. For instance, USP4 can be ubiquitinated at multiple sites such as the cysteine residues. Auto-deubiquitination can also occur at these sites, which is required for USP4 to interact with CtIP/MRN and promote DNA repair (Wada and Kamitani, 2006; Liu H. et al., 2015; Wijnhoven et al., 2015). Moreover, there are other DUBs such as USP11 and USP15 that also undergo ubiquitination modification and alter their interaction with other proteins. This process can be counteracted by auto-deubiquitination. Studies have shown that the substrate SMAD2/3 can interact with WT USP15, and not with a catalytically dead USP 15 mutant, implying that there may be an auto-deubiquitination-dependent interaction as well (Inui et al., 2011; Wijnhoven et al., 2015). There are many other DUBs including USP18, USP21, USP30, USP44, USP47, USP, PSMD7, PSMD14, AMSH, PRPF8, USPL1 etc which are tightly regulated by interactors (Choudhary et al., 2009; Peschiaroli et al., 2010; Gaudet et al., 2011; Parsons et al., 2011; Zhang et al., 2013; Hutten et al., 2014; Huttlin et al., 2017), but it's not clear whether the PTMs occurring on DUBs and affecting their interactors ( $\mathrm{Li}$ and Seth, 2004; Malakhova et al., 2006; Olsen et al., 2010; Suresh et al., 2010; Visconti et al., 2012; Khan et al., 2015; Lan et al., 2016).

\section{Hydroxylation Alters the Localization of DUBs}

Hypoxia is a commonly encountered physiological stress that can induce an active response in mammalian cells through a transcription factor named hypoxia-inducible factor (HIF) (Schofield and Ratcliffe, 2004; Semenza, 2009). Oxygendependent hydroxylation $(-\mathrm{OH})$ is also a functional PTM that can impact the localization of DUBs by altering their interactome (Sowa et al., 2009; Scholz et al., 2013). For example, when OTUB1 is hydroxylated at the Asn22 residue by factor inhibiting HIF (FIH), the interactome and substrates of OTUB1 are elevated, particularly its interaction with metabolism-associated proteins. This suggests that OTUB1 may function as a possible link between oxygen sensing and metabolic regulation. In addition, the protein stability of OTUB1 is not changed by the hydroxylation of Asn22 (Scholz et al., 2016; Van Damme et al., 2012). Recent studies have identified Cezanne as a novel substrate of the asparaginyl $\beta$-hydroxylase FIH1. Cezanne is hydroxylated at Asn35 of the UBA domain in an oxygen- or FIH1-dependent manner, which inhibits the binding of $\mathrm{Ub}$ to Cezanne (Mader et al., 2020).

\section{PTMS CAN REGULATE THE SPECIFICITY AND ACTIVITY OF DUBS}

DUBs are active and substrate-specific enzymes. However, certain DUBs require Ub-binding or modulation to form their active conformation. In a cellular environment, DUB activity is tightly regulated because uncontrolled activation can be detrimental for cells (Reyes-Turcu et al., 2009; Li and Reverter, 2021). Herein, PTMs are a critical approach to regulate the activity and specificity of DUBs, and also play an important role in DUBsrelated diseases.

\section{Phosphorylation Induces DUB Activity and Specificity}

Phosphorylation is a central PTM that can regulate the function of a variety of DUBs by directly influencing its catalytic activity (López-Otín and Hunter, 2010). Phosphorylation of DUBs has been shown to modulate, activate, and inhibit the activity of various DUBs (Figure 3C).

Firstly, phosphorylation can activate or enhance the activity of several DUBs. OTUD5 is a relatively well studied protease, and phosphorylation is known to activate its catalytic activity (Figure 3C). OTUD5 purified from E. coli is inactive, but can be activated when the Ser177 residue of OTUD5 is phosphorylated by CKII instead of by mimic phosphorylation (Dephoure et al., 2008; Mayya et al., 2009). Phosphorylation alone does not alter the structure of OTUD5, however, its structure changes significantly upon $\mathrm{Ub}$ binding. Therefore, phosphorylation is vital for the recognition of Ub by OTUD5. Structural studies have shown that the phosphate group can form a salt bridge with the distal end of the Ub substrate and the highly inwardly oriented $a 6$ fragment of the OUT domain (Figure 4A). This pattern of substrate recognition is unique among DUBs containing PTMs with known structures (Komander, 2010; Huang et al., 2012). Interestingly, phosphorylation-driven conformational changes are a typical feature of protein kinase activation (Taylor and Kornev, 2011). OTUD5 activation is similar to protein kinases. Therefore, OTUD5 is an archetype that establishes a new connection between two critical posttranslational modifications, phosphorylation and ubiquitination. The catalytic activity of DUB depends entirely on the phosphorylation of a single suitable site (Huang et al., 2012).

USP14, a DUB that reversibly binds to the proteasome, can negatively regulate the proteasome by trimming the $\mathrm{Ub}$ chain on the proteasome-bound substrate. Purified and recombinant USP14 is inactive and is largely activated when bound to the proteasome (Borodovsky et al., 2001; Koulich et al., 2008; Lee et al., 2010). However, a study found that proteasome-free forms of USP14 do exist in the cell, and their physiological functions 


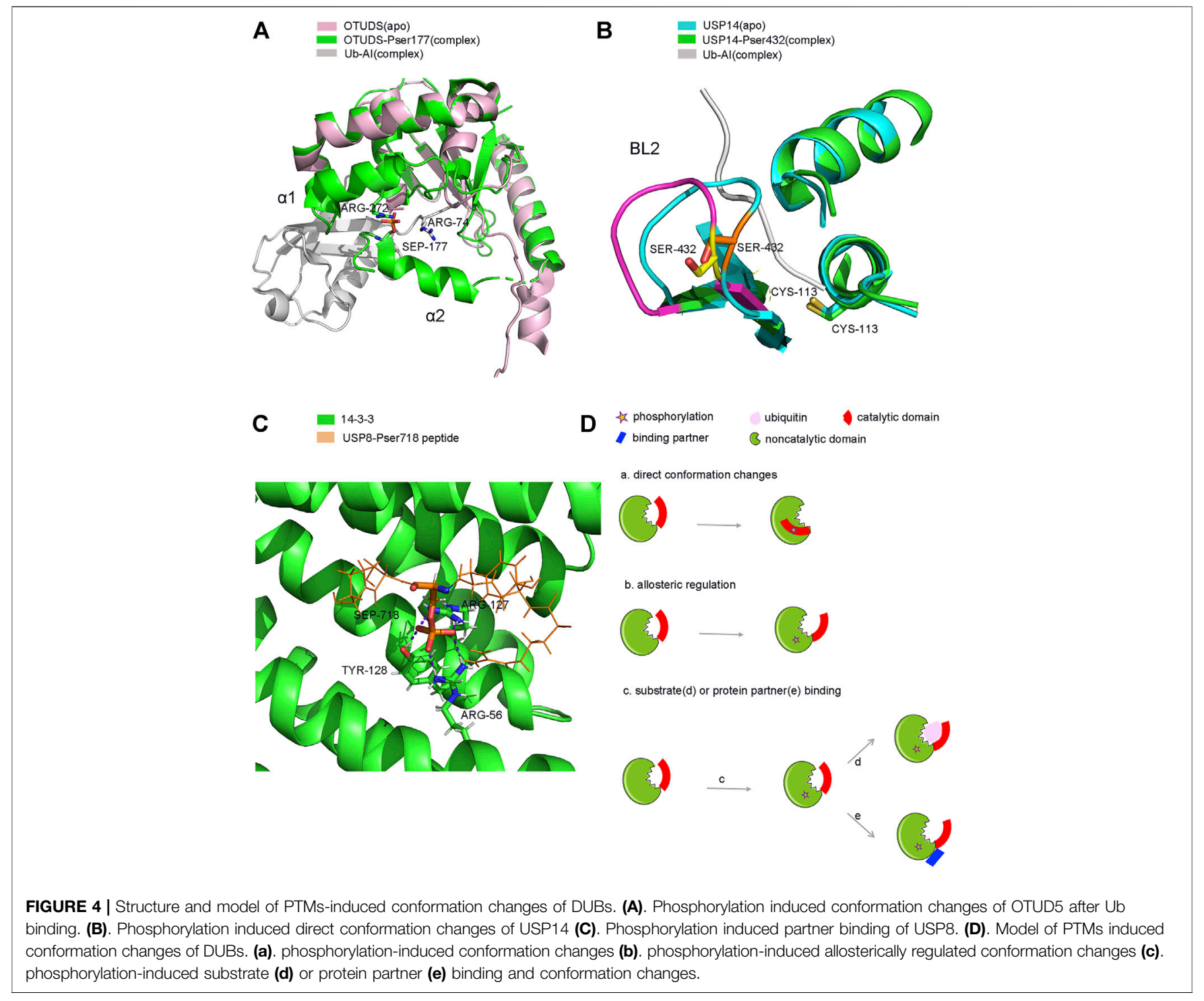

remain unknown (Zhou H. et al., 2013). Until 2015, studies showed that AKT-induced phosphorylation of USP14 at residue Ser432 or a mimetic phosphorylation at Ser432 can significantly promote the activity of USP14 (Figure 3C). It was able to hydrolyse K48, K63 di-Ub, Ub-AMC, but not linear di-Ub (Di-Ub). Simultaneously, Ser432 phosphorylation or binding to the proteasome can synergistically increase the activity of USP14, suggesting that there are two different mechanisms to regulate the activity of USP14 (Xu et al., 2015). Therefore, upon phosphorylation at Ser432, USP14 can release self-inhibition and promote hydrolysis of the Ub substrates (Figure 4B). It is different from the mechanism by which the proteasome activates USP14.

Furthermore, phosphorylation of USP37 is a cell cycledependent event. It is induced in the G1 phase, peaks in the G1/S phase, and is no longer phosphorylated in the later stages of mitosis. Thus, USP37 plays an important role in cell cycle regulation (Huang et al., 2011). USP37 binds to the substrate adaptor $\mathrm{CDH} 1$ and removes the polyubiquitin chain, which is the degradation signal, from cyclin A (Lukas et al., 1999). The USP37 activity maximizes when Ser628 of USP37 is phosphorylated by CDK2 (Huang et al., 2011) (Figure 3C). One possible mechanism is that phosphorylation can enhance the binding of USP37 to the substrate by altering the conformation of its $\mathrm{Ub}$ interaction motif. However, how Ser628 phosphorylation promotes the activity of USP37 remains unknown. A detailed structural analysis of phosphorylated USP37 may be required to reveal this mechanism.

Studies have also reported that phosphorylation of A20 could promote the cleavage of K63-linked polyubiquitin chains by its OTU domain. Results showed that recombinant A20 purified from E. coli failed to cleave K63-linked tetraubiquitin (Komander and Barford, 2008), whereas A20 purified from mammalian cells cleaved the K63-polyubiquitin chain. In fact, I $\kappa \mathrm{K} \beta$-mediated phosphorylation of $\mathrm{A} 20$ at the Ser381 residue plays an essential role in facilitating cleavage of K63-linked 
polyubiquitin chains by A20 (Figure 3C). This also clarifies the molecular mechanism of A20 in suppressing inflammationassociated signalling pathways (Lin et al., 2008; Wertz et al., 2015).

Similarly, USP10 purified from E. coli exhibits a defective deubiquitinase activity. The deubiquitinase activity of USP10 was significantly increased after USP10 was phosphorylated at the Ser76 residue by AMPK under energy stress (Figure 3C). Subsequently, it deubiquitinates AMPK and facilitates the further activation of AMPK, forming a feedforward loop (Hardie, 2011; Hornbeck et al., 2015). The phosphorylated Ser76 site lies in a predicted unstructured region external to the catalytic UCH domain of USP10 (Bhattacharya et al., 2020). Phosphorylation may promote the activity of USP10 by inducing conformational changes in USP10 or affecting the recognition and binding of USP10 to Ub substrates. In this context, the detailed structure of the phosphorylated form of USP10 is important for elucidating the essential role of phosphorylation in modulating the catalytic activity of USP10 (Deng et al., 2016).

TCR-dependent phosphorylation at residues Ser1600 of USP9X enhances its catalytic activity (Figure 3C) and makes it competent to deubiquitinate ZAP70 (LoGrasso et al., 1996; Mayya et al., 2009; Mayya and Han, 2009; Naik et al., 2014). Ser1600 lies within the UCH hydrolase domain of USP9X, and phosphorylation at Ser1600 confers USP9X with an increased catalytic activity (Paudel et al., 2019). USP9X functions as a positive regulatory switch during $\mathrm{T}$ lymphocyte activation by eliminating the monoubiquitination inhibition of ZAP70 (Naik and Dixit, 2016).

In contrast, phosphorylation can also exhibit an inhibitory effect on the catalytic activity of DUBs, as demonstrated in CYLD. CYLD, a tumour suppressor (Massoumi, 2011), can remove K63linked Ub chains from a large number of inflammation-related substrates, such as TRAF2 and TRAF6, and inhibit inflammatory signalling and cell cycle progression by inactivating these substrates (Brummelkamp et al., 2003; Kovalenko et al., 2003). IKKe-induced phosphorylation at Ser418 of CYLD decreased its activity (Figure 3C) and completely blocked CYLD-mediated deubiquitination of TRAF2, thereby promoting tumorigenesis in breast cancer cells (Hutti et al., 2009; Massoumi, 2011; Eguether et al., 2014).

Compared to CYLD, VRK2 kinase-mediated phosphorylation of USP25 at residues Thr680, Thr727, and Ser745 also suppresses the deubiquitinating activity of USP25 (Kim et al., 2015) (Figure 3A). Impaired USP25 destabilizes the molecular chaperone TRiC protein, which is responsible for monitoring protein misfolding. TRiC functions as the first line of defense to prevent misfolded protein aggregation in neurodegenerative diseases (Tam et al., 2006; Kim et al., 2014). This indicates that inhibition of USP25 phosphorylation may have a potential role in the treatment of neurodegenerative diseases (Kim et al., 2015).

Additionally, aggregation of Ataxin3 can cause dendritic and synaptic loss in cultured neurons, and is involved in spinocerebellar ataxia type 3, also known as Machado-Joseph disease (Kawaguchi et al., 1994). A study demonstrated that glycogen synthase kinase $3 \beta \quad$ (GSK $3 \beta$ )-induced phosphorylation of Ataxin3 at Ser256 can regulate the aggregation of Ataxin3 (Fei et al., 2007). The phosphorylation of Ataxin3 at the Ser12 residue adjacent to the catalytic domain can also counter the neuromorphological defects caused by the decrease in deubiquitinase activity. Additionally, mutations in the Ser12 residue can reduce protein aggregation, and neuronal and synapse loss, and are implicated in neurodegenerative diseases (Matos et al., 2016).

UCHL3 is phosphorylated at Ser75 and activated by ATM upon DNA damage. In turn, UCHL3 deubiquitinates RAD51 and promotes the binding between BRCA2 and RAD51, which play an important role in DNA damage repair and the resistance of cancer cells to radiation and chemotherapy (Davies et al., 2001; Luo et al., 2016; Zhao et al., 2017). Therefore, inhibition of UCHL3 activity or UCHL3 phosphorylation may provide new insights in cancer therapy. Obviously, the biological role and mechanism of UCHL3 phosphorylation has not been fully understood yet, and this requires further research (Misaghi et al., 2005).

Phosphorylation can inhibit the activity of USP8 in a cell cycle-dependent manner. In the interphase stage of cell division, the Ser680 residue of USP8 is phosphorylated, which enables USP8 to bind to the 14-3-3 protein This binding in turn inhibits the catalytic activity of USP8 (Mizuno et al., 2007) (Figure 3C). Meanwhile, in the M phase, the dephosphorylation of USP8 at Ser680 can enhance its catalytic activity (Mukai et al., 2008; Pohl and Jentsch, 2008). Moreover, a mutation in the Ser680 residue can also enhance the activity of USP8, including hydrolysis of K48 or K63 polyubiquitin chains and intracellular substrates both in vivo and in vitro. It is plausible that after the 14-3-3 protein allosterically binds to phosphorylated USP8; USP8 undergoes a conformational change from an active state to an inhibitory state (Centorrino et al., 2018). It is also possible that the binding of the 14-3-3 protein covers the catalytic domain of USP8 and prevents the substrate from entering the catalytic centre of the enzyme. Moreover, the binding site of the 14-3-3 protein on USP8 is very close to the catalytic active centre of USP8, which is only about 60 amino acids apart (Mizuno et al., 2007; Ernst et al., 2013). Additionally, EGFR kinase-induced phosphorylation of USP8 at Tyr717 and Tyr810 residues elevates its activity and activates the EGF receptor kinase-mediated inhibition of ciliogenesis. This process plays a critical role in the regulation of ciliogenesis in dividing cells (Row et al., 2009; Kasahara et al., 2018). Therefore, further structural studies may provide us with new insights into the molecular mechanism of phosphorylation-dependent alterations in USP8 (Figure 4C).

Interestingly, phosphorylation can alter the specificity of DUBs toward hydrolysis of Ub chains. A study found that OTUD4 purified from E. coli tends to hydrolyse K48-linked Ub chains, whereas OTUD4 purified from HEK293T cells preferentially hydrolyse K63-linked Ub chains (Mevissen et al., 2013; Zhao et al., 2015). Studies have confirmed that casein kinase II (CK2) induces the phosphorylation of OTUD4 at residues Ser202, which is adjacent to the catalytic OTU domain (Olsten and Litchfield, 2004). Therefore, phosphorylation alters the tendency of OTUD4 to hydrolyse Ub chains from that of 
K48- to K63-linked Ub chains. This process plays an essential role in innate immune signalling pathways (Zhao et al., 2018).

Therefore, PTMs such as phosphorylation can alter the activity of DUBs and its specificity towards Ub linkage types (Table 2). This is an exciting new concept that may be widely adopted in the future. Furthermore, it will provide a unique perspective for understanding how DUBs regulate different physiological processes through PTMs such as phosphorylation. Ubiquitylation can both positively or negatively regulate DUBs activity.

\section{Ubiquitylation}

DUBs can cleave the Ub chains on substrates and play an essential role in many cellular processes. Interestingly, DUBs themselves can also be subjected to ubiquitination modifications. This type of modification is emerging as a critical regulator of DUB function as it exhibits both negative and positive regulatory effects.

Studies have shown that ubiquitination can positively regulate the activity of DUBs, such as that observed in the MJD subfamily of DUBs. Ataxin3 is a member of the MJD subfamily and is a DUB implicated in protein quality control. The activity of Ataxin3 is closely related to neurodegenerative disorders (Kawaguchi et al., 1994; Stevanin et al., 1995; Weishaupl et al., 2019). The ubiquitination of Lys117 near the catalytic groove of Ataxin3 can enhance its Ub chain cleavage activity (Figure 3D), but does not alter its preference for K63-linked Ub chains (Todi et al., 2010; Todi et al., 2009). JosD1, another member of the MJD subfamily, exhibits limited cleavage activity toward K48- or K63linked Ub chains. In contrast, the ubiquitinated forms of JosD1 at the Lys136 residue exhibit enhanced cleavage activity of Ub chains (Figure 3D). This result indicates ubiquitination can positively regulate the activity of JosD1, and that JosD1 plays an important role in membrane dynamics (Seki et al., 2013).

Moreover, ubiquitination of DUBs can also negatively regulate their activity. UCHL1, a member of the UCH subfamily of DUBs, is highly expressed in neurons, and is involved in several neurodegenerative diseases, including Alzheimer's and Parkinson's disease (Bower et al., 1999; Leroy et al., 1998). Studies have shown that the monoubiquitination of residues near the active site of UCHL1 can restrict its enzymatic activity (Figure 3D) by inhibiting the binding of $\mathrm{Ub}$ to UCHL1. Therefore, the permanent monoubiquitination status of UCHL1 prevents its deubiquitinase activity and reduces Ub levels in cells. Interestingly, UCHL1 can intramolecularly modulate its monoubiquitination status, which depends on its hydrolytic activity (Osaka et al., 2003; Meray and Lansbury, 2007).

Interestingly, auto-deubiquitination can occur on some DUBs after they are ubiquitinated. USP6, a member of the USP subfamily, was initially identified as an oncogene (Madan et al., 2016; Nakamura et al., 1992). A study demonstrated that USP6 is mono- or poly-ubiquitinated, which promotes its auto-deubiquitination through direct binding to $\mathrm{Ca}^{2+}$ / Calmodulin (Shen C. et al., 2005). USP4 was first identified as a protein with a high sequence similarity to USP6 and has been thought to function as a DUB (Gupta et al., 1993). Studies have shown that wild-type USP4 is mono- or poly-ubiquitinated by
Ro52. The ubiquitination level of a mutated form of USP4 (at the active site Cys311) was considerably elevated (Wada and Kamitani, 2006). These results indicated that selfdeubiquitination occurred in wild-type USP4, and the mutation may inhibit the self-deubiquitination activity of USP4 (Wada and Kamitani, 2006). Simultaneously, a study showed that USP7 can also be ubiquitinated at the Lys869 residue (Figure 3D), but its function is unclear (FernándezMontalván et al., 2007).

\section{SUMOylation Inhibits the Activity of DUBs}

SUMOylation is also an essential and reversible PTM with significant roles in various cellular processes (GeissFriedlander and Melchior, 2007). Similar to ubiquitination, SUMOylation is a process involving the conjugation of a small peptide SUMO to the substrates via a hierarchical interplay of three enzymes: SUMO activating enzyme E1, SUMO-conjugation enzyme E2, and SUMO-ligation enzyme E3 (Wilkinson and Henley, 2010). The reversible deSUMOylation enzyme named the SUMO-specific protease can deconjugate SUMO from substrates in a process similar to that of the deubiquitylation process (Kim and Baek, 2009). In addition, a recent study has shown SUMOylation of DUBs usually inhibits its activity.

USP25, a member of the USP subfamily of DUBs, has been reported to be associated with the immune response, cancer, and other diseases (Li et al., 2014; Zhong et al., 2012). The N-terminus of USP25 contains two tandem UIM domains, and SIM and UBA domains (Denuc et al., 2009; Meulmeester et al., 2008). The target proteins of PTMs such as ubiquitination, phosphorylation, and SUMOylation are varied (Hecker et al., 2006; Song et al., 2004) (Figure 3A). SUMOylation at residues Lys99 and Lys141 of the UIM domain can inactivate USP25 and impair the ability of USP25 to hydrolyse the Ub chain by inhibiting the binding of USP25 to Ub chains in vitro (Figure 3C). Conversely, removing the SUMO modification from USP25 can increase its binding to the tetra-Ub chains (Meulmeester et al., 2008).

Coincidentally, USP28 is homologous to USP25 and is upregulated in colon cancer cells and NSCLC cells (Popov et al., 2007a; Valero et al., 2001; Li et al., 2014; Zhang L. et al., 2015). It also contains one UBA and two UIM domains at the $\mathrm{N}$ terminus that are responsible for the addition of SUMO (Zhen et al., 2014). SUMOylation at the Lys99 residue of the UIM domain could inhibit the activity of USP28 (Figure 3C), indicating its potential role in cancer therapy (Diefenbacher et al., 2014; Zhen et al., 2014; Zhang Y. et al., 2015).

CYLD, belonging to the USP subfamily, is ubiquitously expressed and highly conserved, and negatively regulates NF$\kappa B$ activation by TNFR family members (Trompouki et al., 2003). The SUMOylation of CYLD at the Lys40 residue of its $\mathrm{N}$-terminus can also reduce its activity against substrates TRAF2 and TRAF6 (Figure 3C), and block the activation of NF-kB signalling, which plays an essential role in inflammatory reactions (Kobayashi et al., 2015).

Studies have also shown that USP39 plays a vital role in cancer development, including breast cancer and hepatocellular cancer, where upregulation of USP39 was observed (Liu S. et al., 2015; Pan et al., 2015). Furthermore, USP39 can also undergo 
TABLE 2 | Summary of phosphorylation induced DUBs' activity change.

\begin{tabular}{|c|c|c|c|c|c|c|}
\hline DUBs & Kinase & Phosphorylation site & Feature & Structure & Physiology & References \\
\hline OTUD4 & $\begin{array}{l}\text { CK2(casein } \\
\text { kinase II) }\end{array}$ & $\begin{array}{l}\text { Ser202/Ser204 (adjacent to } \\
\text { the OTU domain, and } \\
\text { mimetic phosphorylation can } \\
\text { mildly promote the DUB } \\
\text { activity) }\end{array}$ & $\begin{array}{l}\text { Convert to hydrolysis K63 } \\
\text { from K48 }\end{array}$ & No structure & $\begin{array}{l}\text { Regulate MyD88- } \\
\text { dependent NF-кB signaling }\end{array}$ & Zhao et al. (2018) \\
\hline OTUD5 & $\begin{array}{l}\text { CK2(casein } \\
\text { kinase II) }\end{array}$ & $\begin{array}{l}\text { Ser177 (lies in an } \\
\text { unstructured region of the } \\
\text { protein immediately } \\
\text { preceding the predicted core } \\
\text { OTU domain) }\end{array}$ & $\begin{array}{l}\text { pSer177- OTUD5 showed } \\
\text { robust activity against K48/ } \\
\text { K63 di-ub and good activity } \\
\text { against K11-linked } \\
\text { substrate, while linear di-ub } \\
\text { was not processed }\end{array}$ & $\begin{array}{l}\text { Crystal (pSer177 does not } \\
\text { affect the structure of apo } \\
\text { OTUD5; phosphorylated } \\
\text { loop folds over the ub-al C } \\
\text { terminus to stabilize } \\
\text { enzyme and exclude water } \\
\text { from the active site }\end{array}$ & $\begin{array}{l}\text { A regulator of innate } \\
\text { immunity }\end{array}$ & Huang et al. (2012) \\
\hline OTULIN & $\begin{array}{l}\text { ABL1 (ABL } \\
\text { proto- } \\
\text { oncogene 1) }\end{array}$ & $\begin{array}{l}\text { Tyr56 (adjacent to the OTU } \\
\text { domain) }\end{array}$ & $\begin{array}{l}\text { Promote the interaction of } \\
\text { OTULIN } / \beta \text {-catenin and the } \\
\text { activation of wnt } / \beta \text {-catenin } \\
\text { signaling }\end{array}$ & $\begin{array}{l}\text { Crystal structure of OUT } \\
\text { domain }\end{array}$ & $\begin{array}{l}\text { Playing a critical role in the } \\
\text { triple-negative breast } \\
\text { cancer progression and } \\
\text { metastasis }\end{array}$ & $\begin{array}{l}\text { Keusekotten et al. } \\
\text { (2013); Wang et al. } \\
\text { (2020a) }\end{array}$ \\
\hline A20 & $\mid \kappa K \beta$ & $\begin{array}{l}\text { Ser381, Ser480, Ser565, } \\
\text { Thr625 (substitution of all four } \\
\text { residues alone attenuated } \\
\text { cleavage of K63-linked } \\
\text { tetraubiquitin) }\end{array}$ & $\begin{array}{l}\text { Hydrolysis K48- or K63- } \\
\text { linked tetraubiquitin but not } \\
\text { linear tetraubiquitin }\end{array}$ & $\begin{array}{l}\text { Crystal } \\
\text { FL OTU }\end{array}$ & $\begin{array}{l}\text { A20 phosphorylation } \\
\text { suppresses } \\
\text { Inflammatory signaling }\end{array}$ & Wertz et al. (2015) \\
\hline USP14 & Akt & $\begin{array}{l}\text { Ser432 (within a catalytic } \\
\text { domain, located within BL2, } \\
\text { shifts its position over a } \\
\text { distance of } 3-5 \AA \text { in pSer432 } \\
\text { form compared with inactive } \\
\text { free form, and an adduct } \\
\text { between Ubal-USP14 and } \\
\text { S432E mimetic also promote } \\
\text { USP14 activity) }\end{array}$ & $\begin{array}{l}\text { PSer432 and S432E } \\
\text { mimetic all promote K48/ } \\
\text { K63 di-ub or Ub-AMC } \\
\text { deubiquitination activity, } \\
\text { while linear di-ub was not } \\
\text { cleaved }\end{array}$ & $\begin{array}{l}\text { Crystal } \\
\text { USP domain }\end{array}$ & $\begin{array}{l}\text { S432 phosphorylation and } \\
\text { interaction with proteasome } \\
\text { maybe } \\
\text { Two different regulatory } \\
\text { mechanisms for USP14 }\end{array}$ & Xu et al. (2015) \\
\hline USP37 & $\begin{array}{l}\text { CDK2 in G1/S } \\
\text { cell cycle }\end{array}$ & $\begin{array}{l}\text { Ser682(within a catalytic } \\
\text { domain) }\end{array}$ & $\begin{array}{l}\text { USP37 phosphorylation } \\
\text { correlated with its cell cycle- } \\
\text { specific DUB activity }\end{array}$ & No structure & Cell cycle & Huang et al. (2011) \\
\hline USP8 & Unknown & & $\begin{array}{l}\text { USP8 is catalytically inhibited } \\
\text { in a phosphorylation- } \\
\text { dependent manner by 14-3- } \\
\text { 3s protein binding during the } \\
\text { interphase, while the activity } \\
\text { is enhanced in the M phase } \\
\text { where usp8 was } \\
\text { dephosphorylated }\end{array}$ & $\begin{array}{l}\text { Crystal structure with } \\
\text { USP8 specific inhibitor }\end{array}$ & Cell cycle & $\begin{array}{l}\text { Mizuno et al. } \\
(2007)\end{array}$ \\
\hline USP15 & CDKs & $\begin{array}{l}\text { Thr149/Thr219 (located at } \\
\text { the UBL domain, two sites } \\
\text { are in the linker of DUSP and } \\
\text { UBL domain, affects the } \\
\text { interaction of USP15 to other } \\
\text { protein) }\end{array}$ & $\begin{array}{l}\text { Regulate localization and } \\
\text { interaction with SART3 } \\
\text { protein and spliceosome } \\
\text { deubiquitination }\end{array}$ & $\begin{array}{l}\text { Crystal structure of } \\
\text { SART3-USP15DUSP-UBL }\end{array}$ & $\begin{array}{l}\text { Regulate spliceosome } \\
\text { dynamics }\end{array}$ & Das et al. (2019) \\
\hline USP10 & AMPK & Ser76 & $\begin{array}{l}\text { Remove Lys63-linked } \\
\text { polyubiquitin from the } \\
\text { activation loop of AMPK }\end{array}$ & Unknown structure & Energy stress & Deng et al. (2016) \\
\hline \multirow[t]{3}{*}{ USP13 } & Aurora B & Ser114 & $\begin{array}{l}\text { USP13 controls aurora B } \\
\text { stability via enzymatically } \\
\text { independent mechanisms }\end{array}$ & Unknown structure & Cell cycle & $\begin{array}{l}\text { Esposito et al. } \\
(2020)\end{array}$ \\
\hline & ATM & Thr196 & $\begin{array}{l}\text { USP13 regulates DNA } \\
\text { damage repair by targeting } \\
\text { RAP80 }\end{array}$ & Unknown structure & DNA repair & Li et al. (2017) \\
\hline & CLK3 & Tyr708 & $\begin{array}{l}\text { Enhancing c-Myc } \\
\text { stabilization }\end{array}$ & Unknown structure & $\begin{array}{l}\text { Cholangiocarcinoma } \\
\text { progression }\end{array}$ & Zhou et al. (2020) \\
\hline USP4 & AKT & $\begin{array}{l}\text { Ser445(located at the } \\
\text { minimal catalytic domain } \\
\text { USP4D1D2) }\end{array}$ & $\begin{array}{l}\text { Redirect USP4 subcellular } \\
\text { localization to the plasma } \\
\text { membrane }\end{array}$ & Crystal structure & TGF- $\beta$ signaling, cancer & Zhang et al. (2012) \\
\hline USP7 & CK2 & Ser18 & $\begin{array}{l}\text { Required for the stability of } \\
\text { USP7 }\end{array}$ & Crystal structure & $\begin{array}{l}\text { DNA damage repair } \\
\qquad \text { (Continued }\end{array}$ & $\begin{array}{l}\text { Khoronenkova } \\
\text { et al. (2012) } \\
\text { n following page) }\end{array}$ \\
\hline
\end{tabular}


TABLE 2 | (Continued) Summary of phosphorylation induced DUBs' activity change.

\begin{tabular}{|c|c|c|c|c|c|c|}
\hline DUBs & Kinase & Phosphorylation site & Feature & Structure & Physiology & References \\
\hline USP28 & ATM & Ser67/Ser714 & $\begin{array}{l}\text { Stabilize DNA damage } \\
\text { signaling protein }\end{array}$ & Crystal structure & DNA damage repair & Zhang et al. (2006) \\
\hline USP25 & $\begin{array}{l}\text { SYK tyrosine } \\
\text { kinase }\end{array}$ & $\begin{array}{l}\text { Thr680, Thr727, Ser745 } \\
\text { (adjacent to the catalytic } \\
\text { domain) }\end{array}$ & $\begin{array}{l}\text { Suppress the } \\
\text { deubiquitination activity }\end{array}$ & Crystal structure & Protein stability & Kim et al. (2015) \\
\hline UCHL3 & ATM & Ser75 & $\begin{array}{l}\text { Regulate BRCA2-RAD51 } \\
\text { pathway }\end{array}$ & Crystal structure & DNA damage repair & Luo et al. (2016) \\
\hline CYLD & $\mathbb{I K K} \varepsilon$ & Ser418 & $\begin{array}{l}\text { Inhibit the catalytic activity of } \\
\text { CYLD }\end{array}$ & Crystal structure & Oncogenic transformation & Hutti et al. (2009) \\
\hline
\end{tabular}

SUMOylation at several sites, including Lys6, Lys16, Lys29, Lys51, and Lys73 residues (Figure 3C). Inhibition of SUMOylation of USP39 enhanced the proliferation of cancer cells as it affected the recruitment of tri-snRNP, suggesting that SUMOylation of USP39 plays an essential role in cancer therapy (Wen et al., 2014; Wen et al., 2014).

The MJD subfamily member Ataxin-3 has been shown to undergo SUMOylation at its N-terminal Lys166 residue. SUMOylation does not alter subcellular localization, but promotes apoptosis (Shen L. et al., 2005; Guzzo and Matunis, 2013). Furthermore, the SUMOylation of Lys356 can influence the interaction between Ataxin-3 and p97, which implies its potential role in tumours ( $\mathrm{Ge}$ et al., 2015). However, the precise mechanisms of this process are still unknown (Dantuma and Hoppe, 2012; Zhou YF. et al., 2013; Almeida et al., 2015).

\section{Oxidation Inhibits the Catalytic Activity of DUBs}

Reactive oxygen species (ROS) and by-products of mitochondrial oxidative metabolism are continuously produced in eukaryotic cells (Poyton et al., 2009). Deregulated ROS levels are linked to various human diseases, including cancer, Alzheimer's disease, and aging (Benhar et al., 2002; Butterfield and Boyd-Kimball, 2004; Hekimi et al., 2011). As most members of DUB families are reduced cysteine proteases, it is reasonable that DUBs can be regulated by ROS. Studies have shown that many members of the OTU, UCH and USP subfamily of DUBs can be reversibly inactivated by oxidation (Lee et al., 2013). Until now, researchers have purified about $30 \%$ of known DUBs, including members of the OTU, UCH and USP subfamilies, and most of them did not show any significant activity due to oxidation during purification. However, after DTT treatment, the activity of the DUBs were enhanced, indicating that oxidation can inhibit the catalytic activity of DUBs.

For example, purified USP19 exhibits a deubiquitinase weak activity. However, it can be activated by DTT treatment under reducing conditions and exhibits the ability to cleave $\mathrm{K} 48$-diUb or Ub-AFC (Mei et al., 2011). Nevertheless, when treated with $\mathrm{H}_{2} \mathrm{O}_{2}$, the deubiquitinase activity was completely abolished as oxidation occurs on cysteine residues in the catalytic domain (Figure 3D). At the same time, this inactivation process can be reversed by addition of DTT (Lee et al., 2013).
Furthermore, some purified DUBs such as USP7, CYLD, and UCHL1 are active, but their activities can be further enhanced by adding DTT (Figure 3D). In contrast to USP19, USP7 and UCHL1 were more resistant to inhibition by $\mathrm{H}_{2} \mathrm{O}_{2}$ at $\mathrm{pH} 7.4$, which indicates that the sensitivity of DUBs to oxidative inhibition depends on the original activity during which the deprotonation of cysteine in the catalytic domain occurs (Lee et al., 2013).

Notably, there are some purified DUBs that have no detectable activity with or without DTT, such as USP1, USP14, and USP28. These DUBs may require certain cofactors for their activity (Cohn et al., 2007). As for USP1, its activation requires the cofactor UAF1. The purified UAF1USP1 complex was indeed active in the Ub-AFC assay, and the activity was strongly and reversibly inhibited by $\mathrm{H}_{2} \mathrm{O}_{2}$. Interestingly, the interaction of USP1 and UAF1 was not affected by $\mathrm{H}_{2} \mathrm{O}_{2}$, suggesting that the inhibition is likely caused by oxidation of the catalytic active site of USP1, which is consistent with other DUBs (Cotto-Rios et al., 2012; Huang et al., 2012; Lee et al., 2013).

Similar to that of the USP family, reversible oxidation can also occur on the members of the OTU subfamily of DUBs, such as OTUD7B, OTUD1, OTUD2, OTUD3, OTUD5, and OTUD6B. This indicates that it is a common regulatory mechanism of deubiquitinase activity (Kulathu et al., 2013).

\section{THE THERAPEUTIC POTENTIAL OF TARGETING PTMS IN DUBS}

Many DUBs undergo one or more PTMs, including phosphorylation, ubiquitination, SUMOylation, and oxidation, leading to changes in activation, inhibition, stability, or localization of these DUBs. These PTMs play a crucial role in the regulation of DUB and dysregulation of this process is associated with many diseases, including cancer, DDR, inflammatory, and neurodegenerative diseases (Table 3).

\section{PTMs of DUBs Are Closely Related to Cancers}

PTMs in DUBs can promote cancer progression. A study demonstrated that AKT-mediated phosphorylation of USP4 
TABLE 3 | PTMs of DUBs induced cellular effects and disorders.

\begin{tabular}{|c|c|c|c|c|c|}
\hline Disorders & DUBs & PTMs & Cellular effects & Disorder type & References \\
\hline \multirow[t]{15}{*}{ Cancer } & USP4 & $\begin{array}{l}\text { Phosphorylation } \\
\text { (tumor promoter) }\end{array}$ & PI (3)K-AKT; enhanced TGF- $\beta$ - signaling & Breast cancer & Zhang et al. (2012) \\
\hline & USP10 & $\begin{array}{l}\text { Phosphorylation } \\
\text { (tumor suppressor) }\end{array}$ & $\begin{array}{l}\text { ATM-Mdm2; down-regulated p53 } \\
\text { signaling }\end{array}$ & Tumor without mutation of p53 & Yuan et al. (2010) \\
\hline & OTULIN & $\begin{array}{l}\text { Phosphorylation } \\
\text { (tumor promoter) }\end{array}$ & $\begin{array}{l}\text { ABL1/c-Abl; increased OTULIN/ } \\
\beta \text {-catenin interaction; activation of wnt/ } \\
\beta \text {-catenin signaling }\end{array}$ & Triple-negative breast cancer & $\begin{array}{l}\text { Wang et al. (2020b); Wang and } \\
\text { Wu (2020) }\end{array}$ \\
\hline & USP13 & $\begin{array}{l}\text { Phosphorylation } \\
\text { Ser114 (tumor } \\
\text { suppressor) }\end{array}$ & $\begin{array}{l}\text { Aurora B phosphorylates USP13 and } \\
\text { promotes the interaction between } \\
\text { USP13 and aurora B. USP13, in turn, } \\
\text { can deubiquitinate aurora B, proper } \\
\text { regulation of aurora B on cell cycle }\end{array}$ & $\begin{array}{l}\text { Cancers where aurora B } \\
\text { overexpression }\end{array}$ & Esposito et al. (2020) \\
\hline & USP13 & $\begin{array}{l}\text { Phosphorylation } \\
\text { Thr196 (tumor } \\
\text { promoter) }\end{array}$ & $\begin{array}{l}\text { ATM induced phosphorylation form of } \\
\text { USP13 can deubiquitinate RAP } 80 \text { and } \\
\text { prompt DNA damage repair response }\end{array}$ & Ovarian cancer & Li et al. (2017) \\
\hline & USP13 & $\begin{array}{l}\text { Phosphorylation } \\
\text { Tyr708 (tumor } \\
\text { promoter) }\end{array}$ & $\begin{array}{l}\text { Phosphorylation of USP13 at Tyr708 } \\
\text { induced by CLK3 promotes the } \\
\text { cholangiocarcinoma progression by } \\
\text { activating c-Myc mediated purine } \\
\text { synthesis }\end{array}$ & $\begin{array}{l}\text { Cholangiocarcinoma with CLK3 } \\
\text { mutation }\end{array}$ & Zhou et al. (2020) \\
\hline & CYLD & $\begin{array}{l}\text { Phosphorylation } \\
\text { (tumor promoter) }\end{array}$ & $\begin{array}{l}\text { IKK } \varepsilon \text {-induced phosphorylation of CYLD } \\
\text { decreased the activity of it and } \\
\text { completely blocks the CYLD-mediated } \\
\text { deubiquitination of TRAF2, thereby } \\
\text { promoting the transformation and } \\
\text { progression of breast cancer cell }\end{array}$ & Breast cancer & Hutti et al. (2009) \\
\hline & USP28 & $\begin{array}{l}\text { SUMOylation (tumor } \\
\text { suppressor) }\end{array}$ & $\begin{array}{l}\text { SUMOylation at Lys99 residues of } \\
\text { USP28 could inhibit the activity of } \\
\text { USP28 }\end{array}$ & $\begin{array}{l}\text { Colon cancer cells and NSCLC } \\
\text { cells }\end{array}$ & Masoumi et al. (2016) \\
\hline & USP39 & $\begin{array}{l}\text { SuMOylation (tumor } \\
\text { suppressor) }\end{array}$ & $\begin{array}{l}\text { Inhibition of the SUMOylation of USP39 } \\
\text { can enhance the proliferation of cancer } \\
\text { cells via affecting the recruitment of tri- } \\
\text { snRNP }\end{array}$ & $\begin{array}{l}\text { Breast cancer and } \\
\text { hepatocellular cancer }\end{array}$ & $\begin{array}{l}\text { Masoumi et al. (2016); Liu et al. } \\
\text { (2015b); Pan et al. (2015); Wen } \\
\text { et al. (2014) }\end{array}$ \\
\hline & USP14 & Unknown & Protein turnover & Ovarian and lung cancer & $\begin{array}{l}\text { Wang et al. (2015a); Wu et al. } \\
\text { (2013) }\end{array}$ \\
\hline & UCHL5 & Unknown & Protein turnover & Esophageal and ovarian cancer & $\begin{array}{l}\text { Chen et al. (2012); Wang et al. } \\
\text { (2014) }\end{array}$ \\
\hline & USP11 & Unknown & Unknown & Breast cancer & Bayraktar et al. (2013) \\
\hline & USP8 & Unknown & $\begin{array}{l}\text { Regulation of the recycle of receptor } \\
\text { tyrosine kinases, such as EGFR }\end{array}$ & Lung cancer & Reincke et al. (2015) \\
\hline & $\mathrm{UCH} 37$ & Unknown & Unknown & Carcinoma & Chen et al. (2012) \\
\hline & USP15 & Unknown & $\begin{array}{l}\text { Regulation of the TGF } \beta \text { signaling } \\
\text { pathway }\end{array}$ & $\begin{array}{l}\text { Breast cancer, ovarian cancer, } \\
\text { glioblastoma }\end{array}$ & $\begin{array}{l}\text { Eichhorn et al. (2012); Inui et al. } \\
\text { (2011) }\end{array}$ \\
\hline \multirow[t]{6}{*}{$\begin{array}{l}\text { DNA damage } \\
\text { response }\end{array}$} & USP7 & $\begin{array}{l}\text { Phosphorylation (DNA } \\
\text { repair promoter) }\end{array}$ & $\begin{array}{l}\text { CK2-Mdm2; down-regulated p53 } \\
\text { signalling }\end{array}$ & DNA damage response & Khoronenkova et al. (2012) \\
\hline & USP4 & $\begin{array}{l}\text { Auto-deubiquitination } \\
\text { (DNA repair promoter) }\end{array}$ & $\begin{array}{l}\text { Auto-deubiquitination is required for } \\
\text { USP4 to interact with CtIP/MRN and } \\
\text { promote DNA repair }\end{array}$ & DNA repair & Wijnhoven et al. (2015) \\
\hline & USP1 & $\begin{array}{l}\text { Phosphorylation (DNA } \\
\text { repair promoter) }\end{array}$ & $\begin{array}{l}\text { After USP1 is phosphorylated, the } \\
\text { USP1/UAF complex translocated to the } \\
\text { nucleus and recruit FANCD2/PCNA } \\
\text { substrates to regulate DNA damage } \\
\text { response }\end{array}$ & Tanslesion DNA repair & $\begin{array}{l}\text { Garcia-Santisteban et al. } \\
\text { (2012); Olazabal-Herrero et al. } \\
\text { (2015) }\end{array}$ \\
\hline & UCHL3 & $\begin{array}{l}\text { Phosphorylation (DNA } \\
\text { repair promoter) }\end{array}$ & $\begin{array}{l}\text { ATM-induced phosphorylation form of } \\
\text { UCHL3 deubiquitinates RAD51 and } \\
\text { promote its binding to BRCA2 after DNA } \\
\text { damage }\end{array}$ & $\begin{array}{l}\text { DNA damage repair and } \\
\text { resistance of cancer cell to } \\
\text { chemotherapy }\end{array}$ & Luo et al. (2016) \\
\hline & USP11 & Unknown & Targeted PALB2 & Homologous recombination & Bayraktar et al. (2013) \\
\hline & USP9X & Unknown & Targeted claspin & Replication checkpoint & Murtaza et al. (2015) \\
\hline Inflammatory & A20 & $\begin{array}{l}\text { Phosphorylation } \\
\text { (positive regulator) }\end{array}$ & $\begin{array}{l}\text { IкK } \beta \text {-mediated phosphorylation of } A 20 \\
\text { at residue Ser381 facilitate } A 20 \text { to cleave } \\
\text { K63-linked polyubiquitin chains }\end{array}$ & $\begin{array}{l}\text { Suppress inflammatory } \\
\text { signalling }\end{array}$ & Wertz et al. (2015) \\
\hline
\end{tabular}


TABLE 3 | (Continued) PTMs of DUBs induced cellular effects and disorders.

\begin{tabular}{|c|c|c|c|c|c|}
\hline Disorders & DUBs & PTMs & Cellular effects & Disorder type & References \\
\hline & USP9X & $\begin{array}{l}\text { Phosphorylation } \\
\text { (positive regulator) }\end{array}$ & $\begin{array}{l}\text { TCR-dependent phosphorylation of } \\
\text { USP9X enhances its catalytic activity } \\
\text { and deubiquitinate ZAP70 }\end{array}$ & T Lymphocyte activation & Naik and Dixit (2016) \\
\hline & OTUD4 & $\begin{array}{l}\text { Phosphorylation } \\
\text { (positive regulator) }\end{array}$ & $\begin{array}{l}\text { CKIl-induced phosphorylation of OTUD4 } \\
\text { promote it to hydrolyze the ubiquitin } \\
\text { chain changed from K48 to K63, playing } \\
\text { an essential role in innate immune } \\
\text { signalling }\end{array}$ & Innate immune signalling & Zhao et al. (2018) \\
\hline & CYLD & $\begin{array}{l}\text { SUMOylation (positive } \\
\text { regulator) }\end{array}$ & $\begin{array}{l}\text { SUMOylation of CYLD at Lys } 40 \text { can } \\
\text { reduce its activity and block the } \\
\text { activation of NF-kB signalling }\end{array}$ & Inflammatory & Masoumi et al. (2016) \\
\hline & OTULIN & Unknown & Targeted on NEMO and RIPK1/2 & Inhibit NF-кB signaling & Iwai et al. (2014) \\
\hline & USP18 & Unknown & Expression regulated by IFN $\gamma$ & $\begin{array}{l}\text { Function in haematopoietic cell } \\
\text { differentiation }\end{array}$ & $\begin{array}{l}\text { Malakhov et al. (2002) } \\
\text { Malakhova et al. (2006) }\end{array}$ \\
\hline & USP25 & Unknown & Expression regulated by IRF7 and IFN & $\begin{array}{l}\text { Regulation of innate immune } \\
\text { response to DNA and RNA virus }\end{array}$ & Lin et al. (2015) \\
\hline & USP7 & Unknown & Negative regulator of $\mathrm{NF}-\kappa \mathrm{B}$ activity & $\mathrm{T}_{\text {reg }}$ response & Colleran et al. (2013) \\
\hline & USP21 & Unknown & Stabilize FOXP3 & $\mathrm{T}_{\text {reg }}$ response & Zhang et al. (2013) \\
\hline & Cezanne & Unknown & $\begin{array}{l}\text { Positive regulation of } T \text { cell receptor } \\
\text { signalling and deubiquitinate ZAP70 }\end{array}$ & $T_{H} 1$ and $T_{H} 17$ response & Hu et al. (2016) \\
\hline & TRABID & Unknown & Targeted JMJD2D & $\begin{array}{l}\text { Positive regulator of IL-22 and } \\
\text { IL-23 production }\end{array}$ & Jin et al. (2016) \\
\hline & USP4 & Unknown & $\begin{array}{l}\text { Targeted TAK1 to downregulate NF- } \kappa B \\
\text { activation }\end{array}$ & $\begin{array}{l}\text { Highly expressed in } \mathrm{CD}^{+} \mathrm{T} \text { cells } \\
\text { form rheumatic heart disease }\end{array}$ & Wang et al. (2013) \\
\hline & USP10 & Unknown & Stabilize T-bet & $\begin{array}{l}\text { Highly expressed in PBMCs } \\
\text { from patients with asthma }\end{array}$ & Pan et al. (2014) \\
\hline & USP17 & Unknown & Regulation the stability of IL-33 & $T_{H} 1$ and $T_{H} 17$ response & $\begin{array}{l}\text { Chen et al. (2010); Ni et al. } \\
\text { (2015) }\end{array}$ \\
\hline & USP18 & Unknown & Regulate TAK1-TAB1 interaction & $\begin{array}{l}\text { Expression induced by } \\
\text { cytokines }\end{array}$ & Liu et al. (2013) \\
\hline \multirow[t]{9}{*}{$\begin{array}{l}\text { Neurodegenerative } \\
\text { diseases }\end{array}$} & USP25 & $\begin{array}{l}\text { Phosphorylation } \\
\text { (promoter) }\end{array}$ & $\begin{array}{l}\text { VRK2 kinase-mediated phosphorylation } \\
\text { of USP25 suppresses the } \\
\text { deubiquitinating activity of USP25 and } \\
\text { stabilize the molecular chaperone TRiC } \\
\text { protein }\end{array}$ & $\begin{array}{l}\text { Misfolded protein aggregation in } \\
\text { neurodegenerative disease }\end{array}$ & Kim et al. (2015) \\
\hline & Ataxin3 & $\begin{array}{l}\text { Ubiquitination } \\
\text { (suppressor) }\end{array}$ & $\begin{array}{l}\text { Ubiquitination of Ataxin3 can enhance its } \\
\text { ubiquitin chain cleavage activity and } \\
\text { improve protein quality control }\end{array}$ & $\begin{array}{l}\text { Closely related to the } \\
\text { neurodegenerative disorder }\end{array}$ & Todi et al. (2010) \\
\hline & Ataxin3 & $\begin{array}{l}\text { Phosphorylation } \\
\text { (suppressor) }\end{array}$ & $\begin{array}{l}\text { Phosphorylation of Ataxin3 can regulate } \\
\text { its aggregation and counter the } \\
\text { neuromorphologic defects by } \\
\text { decreasing its deubiquitinase activity }\end{array}$ & Machado-joseph disease & $\begin{array}{l}\text { Fei et al. (2007; Matos et al. } \\
\text { (2016) }\end{array}$ \\
\hline & UCHL1 & $\begin{array}{l}\text { Ubiquitination } \\
\text { (promoter) }\end{array}$ & $\begin{array}{l}\text { Monoubiquitination of the residues near } \\
\text { the active site of } U \mathrm{CHL} 1 \text { can restrict its } \\
\text { enzymatic activity by inhibiting the } \\
\text { binding of ubiquitin to } \mathrm{UCHL1}\end{array}$ & $\begin{array}{l}\text { Neurodegenerative diseases, } \\
\text { including Alzheimer's and } \\
\text { Parkinson's disease }\end{array}$ & Meray and Lansbury (2007) \\
\hline & USP7 & Unknown & $\begin{array}{l}\text { Antagonizes ubiquitination of } \\
\text { a-Synuclein and regulation of REST } \\
\text { signaling and neuronal differentiation }\end{array}$ & Neurodegeneration disease & Alexopoulou et al. (2016) \\
\hline & USP8 & Unknown & $\begin{array}{l}\text { Regulates mitophagy by cleaving } \\
\text { ubiquitin from parkin }\end{array}$ & Neurodegeneration disease & Durcan et al. (2014) \\
\hline & USP14 & Unknown & $\begin{array}{l}\text { Promotes the clearance of tau or Ataxin3 } \\
\text { protein involved in neurodegeneration }\end{array}$ & Mutation lead ataxia & Wilson et al. (2002) \\
\hline & USP15 & Unknown & Counteract parkin-mediated mitophagy & Glioblastoma & Cornelissen et al. (2014) \\
\hline & USP30 & Unknown & Dysfunction of mitochondrial & Neurodegeneration & Bingol et al. (2014) \\
\hline
\end{tabular}

was associated with poor prognosis in breast cancer patients. A building crosstalk between TGF- $\beta$ and AKT signalling pathways exists, which indicates a potential therapeutic role (Zhang et al., 2012). Additionally, DNA damage-induced $\mathrm{ABL} 1 / \mathrm{c}-\mathrm{Abl}$ (ABL proto-oncogene 1) activation can promote the phosphorylation of OTULIN, which enhances its interaction with $\beta$-catenin and promotes the activation of Wnt/ $\beta$-catenin signalling (Table 3) This mechanism plays a critical role in the triple-negative breast cancer (TNBC) progression, metastasis, and drug resistance to cancer treatments (Douglas and Saleh, 2019; Wang Y. et al., 2020; Wang and Wu, 2020). 
Furthermore, CLK3-induced phosphorylation of the Tyr708 residue in USP13 promotes cholangiocarcinoma progression by activating c-Myc-mediated purine synthesis (Zhou et al., 2020). Moreover, ATM-induced phosphorylation of the Thr196 residue in USP13 after DNA damage functions as an essential regulatory event, and plays a critical role in the resistance of cancer cells to chemotherapy by deubiquitinating RAP80, promoting recruitment of complexes, and eliciting a DDR (Hu et al., 2011; Li et al., 2017) (Table 3).

Additionally, in primary adult T-cell leukemia/lymphoma (ATLL) samples and cell lines, increased IKK-induced CYLD phosphorylation was observed. Both IKK inhibitors and overexpression of kinase-inactive TBK/IKK can lower CYLD phosphorylation and trigger cell death (Table 3 ). These results indicated that phosphorylated CYLD is a crucial regulator of ATLL survival and a potential novel therapeutic target for pharmacologic modification in ATLL (Xu et al., 2020).

In contrast, PTMs of some DUBs act as tumour suppressors. For example, phosphorylated USP10 can deubiquitinate and stabilize p53 by reversing its nuclear export and Mdm2induced degradation. Therefore, phosphorylated USP10 can inhibit the growth of tumour cells without inducing mutations in p53 (Table 3), which implies that phosphorylation of USP10 has potential therapeutic effects in tumours. Additionally, kinase Aurora B induced phosphorylation of the Ser114 residue in USP13 prevents several major human cancers by promoting its interaction with partners and stability (Esposito et al., 2020). A study showed that SUMOylation at Lys99 residues of USP28 could inhibit the activity of USP28 (Table 3), indicating potential therapeutic role in colon cancer cells and NSCLC cells (Diefenbacher et al., 2014; Zhen et al., 2014; Zhang L. et al., 2015). Furthermore, inhibition of the SUMOylation of USP39 can enhance the proliferation of cancer cells including breast and hepatocellular cancer via affecting the recruitment of trisnRNP, suggesting that SUMOylation of USP39 has an essential role in cancer therapy (Wen et al., 2014; Liu H. et al., 2015; Pan et al., 2015) (Table 3).

Additionally, there are many other DUBs which are closely related to cancer and other diseases (Li et al., 2002; Xu et al., 2014; Yuan et al., 2015; Harrigan et al., 2018). For instance, dysregulation of USP14 can lead ovarian and lung cancer (Mines et al., 2009; Wu et al., 2013; Wang Y. et al., 2015), and abnormal of UCHL5 can also cause ovarian and esophageal cancer (Chen et al., 2012; Wang et al., 2014). Study found dysregulation of USP11 is related to breast cancer, but the mechanism underlying that is not clear (Bayraktar et al., 2013). Also, dysregulation of the recycle of tyrosine kinase like epidermal growth factor receptor (EGFR) by USP8 cause the development of lung cancer (Reincke et al., 2015). Moreover, abnormal regulation of the TGF $\beta$ signaling pathway by USP 15 can lead the occurrence of glioblastoma, breast cancer, and ovarian cancer (Inui et al., 2011; Eichhorn et al., 2012; Hayes et al., 2012). In addition, the expression of UCH37 is closely related to the progression of human esophageal squamous cell carcinoma (Chen et al., 2012). However, if they are PTMs- mediated disorders or not and which kind of PTMs mediated the disorder was still not clear. Therefore, further investigations need to be done to clarify the corelation between DUBs-related disorders and PTMs.

\section{PTMs of DUBs Promote DNA Repair}

PTMs of DUBs plays vital roles in DNA repair after exposure to genotoxic agents or chemotherapy. Studies have shown that USP7 phosphorylation promotes the deubiquitination and stabilization of $\mathrm{Mdm} 2$, which in turn leads to the degradation and downregulation of p53 (Table 3) (Khoronenkova and Dianov, 2012; Khoronenkova et al., 2012). Also, the auto-deubiquitination of USP4 is required for USP4 to interact with CtIP/MRN and promote DNA repair (Wada and Kamitani, 2006; Wijnhoven et al., 2015). Additionally, ATM-induced phosphorylation of UCHL3 occurs after DNA damage, which in turn deubiquitinates RAD51 and promotes the binding between BRCA2 and RAD51 (Table 3). Thus, these processes play an important role in DNA damage repair and the resistance of cancer cells to radiation and chemotherapy (Adelina A. et al., 2001; Luo et al., 2016; Zhao et al., 2017). There are some other DUBs such as USP11, USP28 and USP9X were reported to be closely related to DNA repair, but if it is the PTMs induced or not was not clear until now (Zhang et al., 2006; Wiltshire et al., 2010; Bayraktar et al., 2013; Homan et al., 2014; Murtaza et al., 2015).

\section{PTMs of DUBs Positively Regulate Inflammation}

PTMs of DUBs can positively regulate the function of DUB in the process of inflammation. Firstly, I $\kappa \mathrm{K} \beta$-mediated phosphorylation of A20 at residue Ser381 plays an essential role in facilitating cleavage of K63-linked polyubiquitin chains by A20, indicating the potential role of A20 in suppressing inflammation-associated signalling (Song et al., 1996; Wertz et al., 2015) (Table 3). In addition, TCR-dependent phosphorylation of USP9X enhances its catalytic activity and makes it competent to deubiquitinate ZAP70, which functions as a positive regulatory switch during $\mathrm{T}$ lymphocyte activation by removing the monoubiquitination inhibition of ZAP70 (Naik and Dixit, 2016) (Table 3). Furthermore, CKII-induced phosphorylation of OTUD4 promoted the preferential hydrolysis of the Ub chain changed from K48- to K63-linked chains, which plays an essential role in innate immune signalling (Zhao et al., 2018). Similarly, the SUMOylation of CYLD at Lys40 residue can also reduce its activity and block the activation of NF-kB signalling, playing an essential role in inflammation (Kobayashi et al., 2015) (Table 3).

There are many other DUBs have been demonstrated to have important role in the inflammation. However, whether PTMs of DUBs occurs and promote its involvement in inflammation response were unclear (Zhang et al., 2018). For example, OTULIN can inhibit the NF- $\kappa \mathrm{B}$ signaling by targeted on NEMO and the receptor-interacting protein kinase $1 / 2$ (RIPK1/2) (Iwai et al., 2014; Damgaard et al., 2016). And the expression of USP18 was regulated by interferon gamma (IFN $\gamma$ ) 
and play an important role in haematopoietic cell differentiation (Malakhov et al., 2002). Meanwhile, expression of USP25 was regulated by interferon regulatory factor 7 (IRF7) and IFN, and have critical role in the innate immune response to DNA and RNA virus (Lin et al., 2015). USP7 and USP21 play an important role in regulatory $\mathrm{T}$ cell $\left(\mathrm{T}_{\text {reg }}\right)$ response by negatively regulate $\mathrm{NF}$ $\kappa \mathrm{B}$ activity and stabilize the forkhead box p3 (FOXP3) respectively (Colleran et al., 2013; Zhang et al., 2013). Moreover, Cezanne can positively regulate $\mathrm{T}$ cell receptor signaling, playing important role in $\mathrm{T}$ helper cell $1\left(\mathrm{~T}_{\mathrm{H}} 1\right)$ and $\mathrm{T}_{\mathrm{H}} 17$ response (Pareja et al., 2012; Hu et al., 2016). TRABID can positively regulate the production of interleukin 22 (IL-22) and IL-23 by targeting on JMJD2D (Jin et al., 2016). Furthermore, USP4 targeted on TGF $\beta$-activated kinase 1 (TAK1) to downregulate NF- $\kappa \mathrm{B}$ activation, which was highly expressed in $\mathrm{CD}^{+} \mathrm{T}$ cell from rheumatic heart disease (Wang et al., 2013). Similarly, USP10 can stabilize T-bet and highly expressed in the peripheral blood mononuclear cells (PBMCs) from patients with asthma (Pan et al., 2014). USP17 play important role in $\mathrm{T}_{\mathrm{H}} 1$ and $\mathrm{T}_{\mathrm{H}} 17$ response by stabilizing IL-33 (Burrows et al., 2009; Chen et al., 2010; Ni et al., 2015). USP18 can regulate TAK1-TAB1 interaction, and the expression was induced by cytokines (Burkart et al., 2012; Liu et al., 2013). Therefore, DUBs were closely involved in the inflammatory signaling pathway and inflammatory disease. However, if PTMs promote and take part in this process or not still need further study in the future.

\section{PTMs of DUBs Is Closely Related to Neurodegenerative Diseases}

Dysregulation of DUBs can cause various neurodegenerative diseases, including Alzheimer's and Parkinson's disease (Harrigan et al., 2018). Studies demonstrated that PTMs of DUBs can either promote or suppress the progression of neurodegenerative diseases. VRK2 kinase-mediated phosphorylation of USP25 suppressed the deubiquitinating activity of USP2 5 and stabilized the molecular chaperone TRiC (Table 3), leading to the aggregation of misfolded proteins in neurodegenerative diseases (Kim et al., 2014; Kim et al., 2015). Studies showed that the ubiquitination of Lys117 near the catalytic groove of Ataxin3 can enhance its Ub chain cleavage activity and this activity is closely related to neurodegenerative disorders (Todi et al., 2009; Todi et al., 2010) (Table 3). Additionally, studies demonstrated that phosphorylation of Ataxin3 influences its aggregation and counters the neuromorphologic defects occurring due to it by decreasing its deubiquitinase activity (Lim et al., 2006; Scaglione et al., 2013). This mechanism plays an important role in the development of Machado-Joseph disease (Fei et al., 2007; Matos et al., 2016) (Table 3). Monoubiquitination of the residues near the active site of UCHL1 can restrict its enzymatic activity by inhibiting the binding of $\mathrm{Ub}$ to UCHL1 (Table 3), promoting the progression of neurodegenerative diseases, including Alzheimer's and Parkinson's disease (Das et al., 2006; Meray and Lansbury, 2007; Liu et al., 2009).
Additionally, there are many other DUBs which can lead neurodegenerative diseases. For example, study showed that USP7 is also involved in the neurodegeneration through antagonize the ubiquitination of $\alpha$-synuclein and regulate the RE1 silencing transcription factor (REST) signaling pathway (Alexopoulou et al., 2016). Similarly, USP8 is closely related to the development of neurodegeneration via regulating the mitophagy by cleaving the ubiquitin from Parkin (Durcan et al., 2014; Alexopoulou et al., 2016). USP14 can promote the clearance of Tau or Ataxin3 protein which is aggregated in neurodegeneration (Wilson et al., 2002; Homma et al., 2015). Moreover, USP15 plays an important role in glioblastoma by counteracting Parkin-mediated mitophagy (Cornelissen et al., 2014). Study also showed that USP30 is involved in the neurodegenerative disease by leading mitochondrial dysfunction (Bingol et al., 2014). However, whether the regulation effect of PTMs on these DUBs is the reason that lead the occurrence of DUBs-related neurodegenerative diseases still need further study.

\section{DISCUSSION}

Generally, single PTMs regulate the function of DUBs via allosteric regulatory effects that lead to conformation changes or by exposing a new binding site by abolishing original protein-protein interactions (Figure 4D). For example, phosphorylation of USP4 is essential for protein stability, or for forming a complex with itself or another protein partner such as USP15. Meanwhile, phosphorylation can prevent USP4 from being localized in the nucleus and play a vital role in DDR.

Moreover, complex crosstalk between post-translationally modified proteins often occurs; a well-described example are kinases. Under certain conditions, phosphorylation is often necessary to trigger subsequent phosphorylation, ubiquitination, or SUMOylation, and the ubiquitination or methylation of histones may be essential for its acetylation (Hunter, 2007). The crosstalk of post-translationally modified DUBs can be either positive or negative. For instance, the N-terminal of USP25 is a target of a variety of PTMs, including phosphorylation, ubiquitination, SUMOylation, and acetylation (Figure 3A). Phosphorylation of USP25 can decrease its protein level in a proteasomal degradationindependent manner by inhibiting the ubiquitination of USP25. Ubiquitination and SUMOylation occur at the same Lys99 residue of USP25. In addition, ubiquitination and SUMOylation can occur at the same Lys99 residue of USP25. Therefore, there is a potential for opposing functions of activation and inhibition due to the negative crosstalk that might exist between ubiquitination and SUMOylation. At the same time, phosphorylation can promote the interaction of USP1 and its cofactor UAF1, whereas the binding of OTULIN to LUBAC is blocked by phosphorylation.

Recent literature clearly highlights the importance of PTMs in modifying the function of DUBs, and its role in promoting or decreasing the occurrence of diseases. PTMs are therefore 
emerging as a pivotal regulator of DUBs and may provide novel insights toward the biological functions of DUBs. However, the biological role of PTMs on DUBs has not been fully understood yet, and this requires further research. Structural studies will be particularly important in elucidating the biological role of PTMs in DUBs. There is no doubt that these studies will drive DUB-targeted drug discovery (Harrigan et al., 2018).

Recently, several small molecule inhibitors targeted toward different members of DUB subfamilies have been reported. Until now, there are few target-specific inhibitors that have been found (Ritorto et al., 2014). In the last two years, several highly specific inhibitors of USP7 and USP14 have been reported (Lee et al., 2010; Turnbull et al., 2017; Gavory et al., 2018; Wang et al., 2018; Clague et al., 2019). However, as many DUB members were strictly conserved during evolution and have a high sequence similarity between each other, new perspectives are still required to facilitate the development of selective compounds targeted toward DUB. Subsequently, novel insights into the PTMsmediated regulation of the function of DUBs might provide us opportunities to develop efficient drugs targeting DUBs. Combining inhibitors of DUBs and enzymes responsible for regulatory PTMs, such as kinases or phosphatase inhibitors, will provide more efficient entry points for pharmacological intervention strategies. For instance, drugs targeting proteins of the Ub/proteasome and SUMO pathways, such as DUBs and SUMO metabolism enzymes, are either on the way or have already entered clinical trials for cancer therapy (Masoumi et al., 2016). A better understanding of the crosstalk or interplay between these two pathways can lead to the identification of novel anticancer tools for treating diseases in which SUMOylation plays a significant role.

Moreover, several DUBs have been reported to be overexpressed or mutated in cancer resulting in altered activities. As PTMs can regulate the abundance and activity of

\section{REFERENCES}

Alexopoulou, Z., Lang, J., Perrett, R. M., Elschami, M., Hurry, M. E., Kim, H. T., et al. (2016). Deubiquitinase Usp8 Regulates a-synuclein Clearance and Modifies its Toxicity in Lewy Body Disease. Proc. Natl. Acad. Sci. USA 113, E4688-E4697. doi:10.1073/pnas.1523597113

Almeida, B., Abreu, I. A., Matos, C. A., Fraga, J. S., Fernandes, S., Macedo, M. G., et al. (2015). SUMOylation of the Brain-Predominant Ataxin-3 Isoform Modulates its Interaction with P97. Biochim. Biophys. Acta 1852, 1950-1959. doi:10.1016/j.bbadis.2015.06.010

Bayraktar, S., Gutierrez Barrera, A. M., Liu, D., Pusztai, L., Litton, J., Valero, V., et al. (2013). USP-11 as a Predictive and Prognostic Factor Following Neoadjuvant Therapy in Women with Breast Cancer. Cancer J. 19, 10-17. doi:10.1097/PPO.0b013e3182801b3a

Benhar, M., Engelberg, D., and Levitzki, A. (2002). ROS, Stress-Activated Kinases and Stress Signaling in Cancer. EMBO Rep. 3, 420-425. doi:10.1093/emboreports/kvf094

Bertram, K., Agafonov, D. E., Liu, W. T., Dybkov, O., Will, C. L., Hartmuth, K., et al. (2017). Cryo-EM Structure of a Human Spliceosome Activated for Step 2 of Splicing. Nature 542, 318-323. doi:10.1038/nature21079

Bhattacharya, U., Neizer-Ashun, F., Mukherjee, P., and Bhattacharya, R. (2020). When the Chains Do Not Break: the Role of USP10 in Physiology and Pathology. Cell Death Dis 11, 1033. doi:10.1038/s41419-020-03246-7
DUBs, it may serve as an effective target for novel cancer therapeutic approaches. We anticipate that the outcome of DUB-focused regulatory research will help decipher the molecular basis of the pathogenesis of human disorders and thus lead to novel or improved therapeutic strategies. We hope that the paradigms presented in this commentary of how diversification and regulation of PTMs in DUBs are achieved will guide future research.

\section{AUTHOR CONTRIBUTIONS}

YW conceptualized and wrote the manuscript, including the figures and tables. FW and YW discussed the paper and approved the final manuscript.

\section{FUNDING}

This work was supported by Youth Project of Beijing Natural Science Foundation 5214027, the National Key R\&D Program of China 2016YFC0906002, Beijing Institute of Technology Innovative Talents Science and Technology Grant 3160012211907, National Natural Science Foundation of China 31770827, 21736002, 31961133015, Beijing Institute of Technology Young Backbone Teacher Start-up Fund 3160012221905, the Beijing Institute of Technology Research Fund Program for Young Scholars.

\section{ACKNOWLEDGMENTS}

We are grateful to Beiming Yu and Shuo Ning from Beijing Institute of Technology for suggestions and modifications to the language.

Bingol, B., Tea, J. S., Phu, L., Reichelt, M., Bakalarski, C. E., Song, Q., et al. (2014). The Mitochondrial Deubiquitinase USP30 Opposes Parkin-Mediated Mitophagy. Nature 510, 370-375. doi:10.1038/nature13418

Borodovsky, A., Kessler, B. M., Casagrande, R., Overkleeft, H. S., Wilkinson, K. D., and Ploegh, H. L. (2001). A Novel Active Site-Directed Probe Specific for Deubiquitylating Enzymes Reveals Proteasome Association of USP14. EMBO J. 20, 5187-5196. doi:10.1093/emboj/20.18.5187

Bower, J. H., Maraganore, D. M., McDonnell, S. K., and Rocca, W. A. (1999). Incidence and Distribution of Parkinsonism in Olmsted County, Minnesota, 1976-1990. Neurology 52, 1214-1220. doi:10.1212/wnl.52.6.1214

Brummelkamp, T. R., Nijman, S. M., Dirac, A. M., and Bernards, R. (2003). Loss of the Cylindromatosis Tumour Suppressor Inhibits Apoptosis by Activating NF-kappaB. Nature 424, 797-801. doi:10.1038/ nature 01811

Burkart, C., Fan, J. B., and Zhang, D. E. (2012). Two Independent Mechanisms Promote Expression of an N-Terminal Truncated USP18 Isoform with Higher DeISGylation Activity in the Nucleus. J. Biol. Chem. 287, 4883-4893. doi:10. 1074/jbc.M111.255570

Burrows, J. F., Kelvin, A. A., McFarlane, C., Burden, R. E., McGrattan, M. J., De la Vega, M., et al. (2009). USP17 Regulates Ras Activation and Cell Proliferation by Blocking RCE1 Activity. J. Biol. Chem. 284, 9587-9595. doi:10.1074/jbc. M807216200

Butterfield, D. A., and Boyd-Kimball, D. (2004). Amyloid Beta-Peptide(1-42) Contributes to the Oxidative Stress and Neurodegeneration Found in 
Alzheimer Disease Brain. Brain Pathol. 14, 426-432. doi:10.1111/j.1750-3639. 2004.tb00087.x

Cannavo, E., Gerrits, B., Marra, G., Schlapbach, R., and Jiricny, J. (2007). Characterization of the Interactome of the Human MutL Homologues MLH1, PMS1, and PMS2. J. Biol. Chem. 282, 2976-2986. doi:10.1074/jbc. M609989200

Centorrino, F., Ballone, A., Wolter, M., and Ottmann, C. (2018). Biophysical and Structural Insight into the USP8/14-3-3 Interaction. FEBS Lett. 592, 1211-1220. doi:10.1002/1873-3468.13017

Chen, R., Zhang, L., Zhong, B., Tan, B., Liu, Y., and Shu, H. B. (2010). The Ubiquitin-specific Protease 17 Is Involved in Virus-Triggered Type I IFN Signaling. Cell Res 20, 802-811. doi:10.1038/cr.2010.41

Chen, Y., Fu, D., Xi, J., Ji, Z., Liu, T., Ma, Y., et al. (2012). Expression and Clinical Significance of UCH37 in Human Esophageal Squamous Cell Carcinoma. Dig. Dis. Sci. 57, 2310-2317. doi:10.1007/s10620-012-2181-9

Chen, Y. J., Chen, C. M., Twu, N. F., Yen, M. S., Lai, C. R., Wu, H. H., et al. (2009). Overexpression of Aurora B Is Associated with Poor Prognosis in Epithelial Ovarian Cancer Patients. Virchows Arch. 455, 431-440. doi:10.1007/s00428009-0838-3

Cheung, M., and Testa, J. R. (2017). BAP1, a Tumor Suppressor Gene Driving Malignant Mesothelioma. Transl. Lung Cancer Res. 6, 270-278. doi:10.21037/ tlcr.2017.05.03

Cholay, M., Reverdy, C., Benarous, R., Colland, F., and Daviet, L. (2010). Functional Interaction between the Ubiquitin-specific Protease 25 and the SYK Tyrosine Kinase. Exp. Cel Res. 316, 667-675. doi:10.1016/j.yexcr.2009. 10.023

Choudhary, C., Kumar, C., Gnad, F., Nielsen, M. L., Rehman, M., Walther, T. C., et al. (2009). Lysine Acetylation Targets Protein Complexes and Coregulates Major Cellular Functions. Science 325, 834-840. doi:10.1126/ science. 1175371

Clague, M. J., Heride, C., and Urbé, S. (2015). The Demographics of the Ubiquitin System. Trends Cel Biol 25, 417-426. doi:10.1016/j.tcb.2015.03.002

Clague, M. J., Urbé, S., and Komander, D. (2019). Breaking the Chains: Deubiquitylating Enzyme Specificity Begets Function. Nat. Rev. Mol. Cel Biol. 20, 338-352. doi:10.1038/s41580-019-0099-1

Cohn, M. A., Kowal, P., Yang, K., Haas, W., Huang, T. T., Gygi, S. P., et al. (2007). A UAF1-Containing Multisubunit Protein Complex Regulates the Fanconi Anemia Pathway. Mol. Cel 28, 786-797. doi:10.1016/j.molcel.2007.09.031

Colleran, A., Collins, P. E., O'Carroll, C., Ahmed, A., Mao, X., McManus, B., et al. (2013). Deubiquitination of NF-Kb by Ubiquitin-specific Protease-7 Promotes Transcription. Proc. Natl. Acad. Sci. U S A. 110, 618-623. doi:10.1073/pnas. 1208446110

Cornelissen, T., Haddad, D., Wauters, F., Van Humbeeck, C., Mandemakers, W., Koentjoro, B., et al. (2014). The Deubiquitinase USP15 Antagonizes ParkinMediated Mitochondrial Ubiquitination and Mitophagy. Hum. Mol. Genet. 23, 5227-5242. doi:10.1093/hmg/ddu244

Costa, Mdo. C., and Paulson, H. L. (2012). Toward Understanding MachadoJoseph Disease. Prog. Neurobiol. 97, 239-257. doi:10.1016/j.pneurobio.2011. 11.006

Cotto-Rios, X. M., Békés, M., Chapman, J., Ueberheide, B., and Huang, T. T. (2012). Deubiquitinases as a Signaling Target of Oxidative Stress. Cell Rep 2, 1475-1484. doi:10.1016/j.celrep.2012.11.011

Damgaard, R. B., Walker, J. A., Marco-Casanova, P., Morgan, N. V., Titheradge, H. L., Elliott, P. R., et al. (2016). The Deubiquitinase OTULIN Is an Essential Negative Regulator of Inflammation and Autoimmunity. Cell 166, 1215-e20. e20+. doi:10.1016/j.cell.2016.07.019

Dantuma, N. P., and Hoppe, T. (2012). Growing Sphere of Influence: Cdc48/p97 Orchestrates Ubiquitin-dependent Extraction from Chromatin. Trends Cel Biol 22, 483-491. doi:10.1016/j.tcb.2012.06.003

Das, C., Hoang, Q. Q., Kreinbring, C. A., Luchansky, S. J., Meray, R. K., Ray, S. S., et al. (2006). Structural Basis for Conformational Plasticity of the Parkinson's Disease-Associated Ubiquitin Hydrolase UCH-L1. Proc. Natl. Acad. Sci. U S A. 103, 4675-4680. doi:10.1073/pnas.060242810310. 1073/pnas. 0510403103

Das, T., Kim, E. E., and Song, E. J. (2019). Phosphorylation of USP15 and USP4 Regulates Localization and Spliceosomal Deubiquitination. J. Mol. Biol. 431, 3900-3912. doi:10.1016/j.jmb.2019.07.023
Das, T., Shin, S. C., Song, E. J., and Kim, E. E. (2020). Regulation of Deubiquitinating Enzymes by post-translational Modifications. Int. J. Mol. Sci. 21. doi:10.3390/ijms 21114028

Davies, A. A., Masson, J. Y., Mcllwraith, M. J., Stasiak, A. Z., Stasiak, A., Venkitaraman, A. R., et al. (2001). Role of BRCA2 in Control of the RAD51 Recombination and DNA Repair Protein. Mol. Cel 7, 273-282. doi:10.1016/ s1097-2765(01)00175-7

Deng, M., Yang, X., Qin, B., Liu, T., Zhang, H., Guo, W., et al. (2016). Deubiquitination and Activation of AMPK by USP10. Mol. Cel 61, 614-624. doi:10.1016/j.molcel.2016.01.010

Denuc, A., Bosch-Comas, A., Gonzàlez-Duarte, R., and Marfany, G. (2009). The UBA-UIM Domains of the USP25 Regulate the Enzyme Ubiquitination State and Modulate Substrate Recognition. PLOS ONE 4, e5571. e5571. doi:10.1371/ journal.pone.0005571

Dephoure, N., Zhou, C., Villén, J., Beausoleil, S. A., Bakalarski, C. E., Elledge, S. J., et al. (2008). A Quantitative Atlas of Mitotic Phosphorylation. Proc. Natl. Acad. Sci. USA 105, 10762-10767. doi:10.1073/pnas.0805139105

Diefenbacher, M. E., Popov, N., Blake, S. M., Schülein-Völk, C., Nye, E., SpencerDene, B., et al. (2014). The Deubiquitinase USP28 Controls Intestinal Homeostasis and Promotes Colorectal Cancer. J. Clin. Invest. 124, 3407-3418. doi:10.1172/JCI73733

Douglas, T., and Saleh, M. (2019). Post-translational Modification of OTULIN Regulates Ubiquitin Dynamics and Cell Death. Cel Rep 29, 3652-e5. e5. doi:10. 1016/j.celrep.2019.11.014

Durcan, T. M., Tang, M. Y., Pérusse, J. R., Dashti, E. A., Aguileta, M. A., McLelland, G. L., et al. (2014). USP8 Regulates Mitophagy by Removing K6-Linked Ubiquitin Conjugates from Parkin. Embo J. 33, 2473-2491. doi:10.15252/ embj. 201489729

Eguether, T., Ermolaeva, M. A., Zhao, Y., Bonnet, M. C., Jain, A., Pasparakis, M., et al. (2014). The Deubiquitinating Enzyme CYLD Controls Apical Docking of Basal Bodies in Ciliated Epithelial Cells. Nat. Commun. 5, 4585. doi:10.1038/ ncomms5585

Eichhorn, P. J., Rodón, L., Gonzàlez-Juncà, A., Dirac, A., Gili, M., Martínez-Sáez, E., et al. (2012). USP15 Stabilizes TGF- $\beta$ Receptor I and Promotes Oncogenesis through the Activation of TGF- $\beta$ Signaling in Glioblastoma. Nat. Med. 18, 429-435. doi:10.1038/nm.2619

Elliott, P. R., Nielsen, S. V., Marco-Casanova, P., Fiil, B. K., Keusekotten, K. Mailand, N., et al. (2014). Molecular Basis and Regulation of OTULIN-LUBAC Interaction. Mol. Cel 54, 335-348. doi:10.1016/j.molcel.2014.03.018

Ernst, A., Avvakumov, G., Tong, J., Fan, Y., Zhao, Y., Alberts, P., et al. (2013). A Strategy for Modulation of Enzymes in the Ubiquitin System. Science 339, 590-595. doi:10.1126/science.1230161

Esposito, M., Akman, H. B., Giron, P., Ceregido, M. A., Schepers, R., Ramos Paez, L. C., et al. (2020). USP13 Controls the Stability of Aurora B Impacting Progression through the Cell Cycle. Oncogene 39, 6009-6023. doi:10.1038/ s41388-020-01396-8

Faronato, M., Patel, V., Darling, S., Dearden, L., Clague, M. J., Urbé, S., et al. (2013). The Deubiquitylase USP15 Stabilizes Newly Synthesized REST and Rescues its Expression at Mitotic Exit. Cell Cycle 12, 1964-1977. doi:10. $4161 /$ cc. 25035

Fei, E., Jia, N., Zhang, T., Ma, X., Wang, H., Liu, C., et al. (2007). Phosphorylation of Ataxin-3 by Glycogen Synthase Kinase 3beta at Serine 256 Regulates the Aggregation of Ataxin-3. Biochem. Biophys. Res. Commun. 357, 487-492. doi:10.1016/j.bbrc.2007.03.160

Fernández-Montalván, A., Bouwmeester, T., Joberty, G., Mader, R., Mahnke, M., Pierrat, B., et al. (2007). Biochemical Characterization of USP7 Reveals posttranslational Modification Sites and Structural Requirements for Substrate Processing and Subcellular Localization. FEBS J. 274, 4256-4270. doi:10. $1111 / j .1742-4658.2007 .05952 . x$

Garcia-Santisteban, I., Zorroza, K., and Rodriguez, J. A. (2012). Two Nuclear Localization Signals in USP1 Mediate Nuclear Import of the USP1/UAF1 Complex. PLOS ONE 7, e38570. doi:10.1371/journal.pone.0038570

Gaudet, P., Livstone, M. S., Lewis, S. E., and Thomas, P. D. (2011). Phylogeneticbased Propagation of Functional Annotations within the Gene Ontology Consortium. Brief Bioinformatics 12, 449-462. doi:10.1093/bib/bbr042

Gavory, G., O’Dowd, C. R., Helm, M. D., Flasz, J., Arkoudis, E., Dossang, A., et al. (2018). Discovery and Characterization of Highly Potent and Selective 
Allosteric USP7 Inhibitors. Nat. Chem. Biol. 14, 118-125. doi:10.1038/ nchembio. 2528

Ge, F., Chen, W., Qin, J., Zhou, Z., Liu, R., Liu, L., et al. (2015). Ataxin-3 like (ATXN3L), a Member of the Josephin Family of Deubiquitinating Enzymes, Promotes Breast Cancer Proliferation by Deubiquitinating Krüppel-like Factor 5 (KLF5). Oncotarget 6, 21369-21378. doi:10.18632/oncogarget.412810.18632/ oncotarget. 4128

Geiss-Friedlander, R., and Melchior, F. (2007). Concepts in SUMOylation: a Decade on. Nat. Rev. Mol. Cel Biol. 8, 947-956. doi:10.1038/nrm2293

Gully, C. P., Velazquez-Torres, G., Shin, J. H., Fuentes-Mattei, E., Wang, E., Carlock, C., et al. (2012). Aurora B Kinase Phosphorylates and Instigates Degradation of P53. Proc. Natl. Acad. Sci. USA 109, E1513-E1522. doi:10. 1073/pnas.1110287109

Gupta, K., Copeland, N. G., Gilbert, D. J., Jenkins, N. A., and Gray, D. A. (1993). Unp, a Mouse Gene Related to the Tre Oncogene. Oncogene 8, 2307-2310. PMID: 8336951.

Guzzo, C. M., and Matunis, M. J. (2013). Expanding SUMO and UbiquitinMediated Signaling through Hybrid SUMO-Ubiquitin Chains and Their Receptors. Cell Cycle 12, 1015-1017. doi:10.4161/cc.24332

Han, A., Purwin, T. J., and Aplin, A. E. (2021). Roles of the BAP1 Tumor Suppressor in Cell Metabolism. Cancer Res. 81, 1-8. doi:10.1158/0008-5472. CAN-20-3430

Hardie, D. G. (2011). AMP-activated Protein Kinase: an Energy Sensor that Regulates All Aspects of Cell Function. Genes Dev. 25, 1895-1908. doi:10. 1101/gad.17420111

Harrigan, J. A., Jacq, X., Martin, N. M., and Jackson, S. P. (2018). Deubiquitylating Enzymes and Drug Discovery: Emerging Opportunities. Nat. Rev. Drug Discov. 17, 57-78. doi:10.1038/nrd.2017.152

Hayes, S. D., Liu, H., MacDonald, E., Sanderson, C. M., Coulson, J. M., Clague, M. J., et al. (2012). Direct and Indirect Control of Mitogen-Activated Protein Kinase Pathway-Associated Components, BRAP/IMP E3 Ubiquitin Ligase and CRAF/RAF1 Kinase, by the Deubiquitylating Enzyme USP15. J. Biol. Chem. 287, 43007-43018. doi:10.1074/jbc.M112.386938

Hecker, C. M., Rabiller, M., Haglund, K., Bayer, P., and Dikic, I. (2006). Specification of SUMO1- and SUMO2-Interacting Motifs. J. Biol. Chem. 281, 16117-16127. doi:10.1074/jbc.M512757200

Hekimi, S., Lapointe, J., and Wen, Y. (2011). Taking a "Good” Look at Free Radicals in the Aging Process. Trends Cel Biol 21, 569-576. doi:10.1016/j.tcb.2011.06.008

Herhaus, L., Perez-Oliva, A. B., Cozza, G., Gourlay, R., Weidlich, S., Campbell, D. G., et al. (2015). Casein Kinase 2 (CK2) Phosphorylates the Deubiquitylase OTUB1 at Ser16 to Trigger its Nuclear Localization. Sci. Signal. 8, ra35. doi:10. 1126/scisignal.aaa0441

Hershko, A., and Ciechanover, A. (1998). The Ubiquitin System. Annu. Rev. Biochem. 67, 425-479. doi:10.1146/annurev.biochem.67.1.425

Homan, C. C., Kumar, R., Nguyen, L. S., Haan, E., Raymond, F. L., Abidi, F., et al. (2014). Mutations in USP9X Are Associated with X-Linked Intellectual Disability and Disrupt Neuronal Cell Migration and Growth. Am. J. Hum. Genet. 94, 470-478. doi:10.1016/j.ajhg.2014.02.004

Homma, T., Ishibashi, D., Nakagaki, T., Fuse, T., Mori, T., Satoh, K., et al. (2015). Ubiquitin-specific Protease 14 Modulates Degradation of Cellular Prion Protein. Sci. Rep. 5, 11028. doi:10.1102810.1038/srep11028

Hornbeck, P. V., Zhang, B., Murray, B., Kornhauser, J. M., Latham, V., and Skrzypek, E. (2015). PhosphoSitePlus, 2014: Mutations, PTMs and Recalibrations. Nucleic Acids Res. 43, D512-D520. doi:10.1093/nar/gku1267

Hsu, J. Y., Crawley, S., Chen, M., Ayupova, D. A., Lindhout, D. A., Higbee, J., et al. (2017). Erratum: Non-homeostatic Body Weight Regulation through a Brainstem-Restricted Receptor for GDF15. Nature 551, 398-259. doi:10. 1038/nature24481

Hu, H., Wang, H., Xiao, Y., Jin, J., Chang, J. H., Zou, Q., et al. (2016). Otud7b Facilitates T Cell Activation and Inflammatory Responses by Regulating Zap70 Ubiquitination. J. Exp. Med. 213, 399-414. doi:10.1084/jem.20151426

Hu, Y., Scully, R., Sobhian, B., Xie, A., Shestakova, E., and Livingston, D. M. (2011). RAP80-directed Tuning of BRCA1 Homologous Recombination Function at Ionizing Radiation-Induced Nuclear Foci. Genes Dev. 25, 685-700. doi:10.1101/ gad.2011011

Huang, O. W., Ma, X., Yin, J., Flinders, J., Maurer, T., Kayagaki, N., et al. (2012). Phosphorylation-dependent Activity of the Deubiquitinase DUBA. Nat. Struct. Mol. Biol. 19, 171-175. doi:10.1038/nsmb.2206
Huang, T. T., Nijman, S. M., Mirchandani, K. D., Galardy, P. J., Cohn, M. A., Haas W., et al. (2006). Regulation of Monoubiquitinated PCNA by DUB Autocleavage. Nat. Cel Biol. 8, 339-347. doi:10.1038/ncb1378

Huang, X., Summers, M. K., Pham, V., Lill, J. R., Liu, J., Lee, G., et al. (2011). Deubiquitinase USP37 Is Activated by CDK2 to Antagonize APC(CDH1) and Promote S Phase Entry. Mol. Cel 42, 511-523. doi:10.1016/j.molcel.2011. 03.027

Hunter, T. (2007). The Age of Crosstalk: Phosphorylation, Ubiquitination, and beyond. Mol. Cel 28, 730-738. doi:10.1016/j.molcel.2007.11.019

Hutten, S., Chachami, G., Winter, U., Melchior, F., and Lamond, A. I. (2014). A Role for the Cajal-Body-Associated SUMO Isopeptidase USPL1 in snRNA Transcription Mediated by RNA Polymerase II. J. Cel Sci. 127, 1065-1078. doi: $10.1242 /$ jcs. 141788

Hutti, J. E., Shen, R. R., Abbott, D. W., Zhou, A. Y., Sprott, K. M., Asara, J. M., et al. (2009). Phosphorylation of the Tumor Suppressor CYLD by the Breast Cancer Oncogene IKKepsilon Promotes Cell Transformation. Mol. Cel 34, 461-472. doi:10.1016/j.molcel.2009.04.031

Huttlin, E. L., Bruckner, R. J., Paulo, J. A., Cannon, J. R., Ting, L., Baltier, K., et al. (2017). Architecture of the Human Interactome Defines Protein Communities and Disease Networks. Nature 545, 505-509. doi:10.1038/nature22366

Inui, M., Manfrin, A., Mamidi, A., Martello, G., Morsut, L., Soligo, S., et al. (2011). USP15 Is a Deubiquitylating Enzyme for Receptor-Activated SMADs. Nat. Cel Biol. 13, 1368-1375. doi:10.1038/ncb2346

Iwai, K., Fujita, H., and Sasaki, Y. (2014). Linear Ubiquitin Chains: NF-Kb Signalling, Cell Death and beyond. Nat. Rev. Mol. Cel Biol 15, 503-508. doi: $10.1038 / \mathrm{nrm} 3836$

Jin, J., Xie, X., Xiao, Y., Hu, H., Zou, Q., Cheng, X., et al. (2016). Epigenetic Regulation of the Expression of $\mathrm{Il} 12$ and Il23 and Autoimmune Inflammation by the Deubiquitinase Trabid. Nat. Immunol. 17, 259-268. doi:10.1038/ni.3347

Kasahara, K., Aoki, H., Kiyono, T., Wang, S., Kagiwada, H., Yuge, M., et al. (2018). EGF Receptor Kinase Suppresses Ciliogenesis through Activation of USP8 Deubiquitinase. Nat. Commun. 9, 758. doi:10.1038/s41467-018-03117-y

Kawaguchi, Y., Okamoto, T., Taniwaki, M., Aizawa, M., Inoue, M., Katayama, S., et al. (1994). CAG Expansions in a Novel Gene for Machado-Joseph Disease at Chromosome 14q32.1. Nat. Genet. 8, 221-228. doi:10.1038/ng1194-221

Kessler, B. M., and Edelmann, M. J. (2011). PTMs in Conversation: Activity and Function of Deubiquitinating Enzymes Regulated via post-translational Modifications. Cell Biochem. Biophys. 60, 21-38. doi:10.1007/s12013-0119176-6

Keusekotten, K., Elliott, P. R., Glockner, L., Fiil, B. K., Damgaard, R. B., Kulathu, Y., et al. (2013). OTULIN Antagonizes LUBAC Signaling by Specifically Hydrolyzing Met1-Linked Polyubiquitin. Cell 153, 1312-1326. doi:10.1016/j. cell.2013.05.014

Khan, A., Giri, S., Wang, Y., Chakraborty, A., Ghosh, A. K., Anantharaman, A., et al. (2015). BEND3 Represses rDNA Transcription by Stabilizing a NoRC Component via USP21 Deubiquitinase. Proc. Natl. Acad. Sci. U. S. A. 112 , 8338-8343. doi:10.1073/pnas.1424705112

Khoronenkova, S. V., and Dianov, G. L. (2012). Regulation of USP7/HAUSP in Response to DNA Damage: yet Another Role for ATM. Cell Cycle 11, 2409-2410. doi:10.4161/cc.20800

Khoronenkova, S. V., Dianova, I. I., Ternette, N., Kessler, B. M., Parsons, J. L., and Dianov, G. L. (2012). ATM-dependent Downregulation of USP7/HAUSP by PPM1G Activates P53 Response to DNA Damage. Mol. Cel 45, 801-813. doi:10. 1016/j.molcel.2012.01.021

Kim, H., Chen, J., and Yu, X. (2007). Ubiquitin-binding Protein RAP80 Mediates BRCA1-dependent DNA Damage Response. Science 316, 1202-1205. doi:10. 1126/science.1139621

Kim, J. H., and Baek, S. H. (2009). Emerging Roles of Desumoylating Enzymes. Biochim. Biophys. Acta 1792, 155-162. doi:10.1016/j.bbadis.2008.12.008

Kim, S., Lee, D., Lee, J., Song, H., Kim, H. J., and Kim, K. T. (2015). Vaccinia-related Kinase 2 Controls the Stability of the Eukaryotic Chaperonin TRiC/CCT by Inhibiting the Deubiquitinating Enzyme USP25. Mol. Cel. Biol. 35, 1754-1762. doi:10.1128/MCB.01325-14

Kim, S., Park, D. Y., Lee, D., Kim, W., Jeong, Y. H., Lee, J., et al. (2014). Vacciniarelated Kinase 2 Mediates Accumulation of Polyglutamine Aggregates via Negative Regulation of the Chaperonin TRiC. Mol. Cel. Biol. 34, 643-652. doi:10.1128/MCB.00756-13 
Kobayashi, T., Masoumi, K. C., and Massoumi, R. (2015). Deubiquitinating Activity of CYLD Is Impaired by SUMOylation in Neuroblastoma Cells. Oncogene 34, 2251-2260. doi:10.1038/onc.2014.159

Komander, D., and Barford, D. (2008). Structure of the A20 OTU Domain and Mechanistic Insights into Deubiquitination. Biochem. J. 409, 77-85. doi:10. 1042/BJ20071399

Komander, D., Clague, M. J., and Urbé, S. (2009). Breaking the Chains: Structure and Function of the Deubiquitinases. Nat. Rev. Mol. Cel Biol. 10, 550-563. doi:10.1038/nrm2731

Komander, D. (2010). Mechanism, Specificity and Structure of the Deubiquitinases. Subcell. Biochem. 54, 69-87. doi:10.1007/978-1-44196676-6_6

Koulich, E., Li, X., and DeMartino, G. N. (2008). Relative Structural and Functional Roles of Multiple Deubiquitylating Proteins Associated with Mammalian 26S Proteasome. Mol. Biol. Cel 19, 1072-1082. doi:10.1091/mbc.E07-10-1040

Kovalenko, A., Chable-Bessia, C., Cantarella, G., Israël, A., Wallach, D., and Courtois, G. (2003). The Tumour Suppressor CYLD Negatively Regulates NF-kappaB Signalling by Deubiquitination. Nature 424, 801-805. doi:10. 1038/nature01802

Kulathu, Y., Garcia, F. J., Mevissen, T. E., Busch, M., Arnaudo, N., Carroll, K. S., et al. (2013). Regulation of A20 and Other OTU Deubiquitinases by Reversible Oxidation. Nat. Commun. 4, 1569. doi:10.1038/ncomms2567

Lan, X., Atanassov, B. S., Li, W., Zhang, Y., Florens, L., Mohan, R. D., et al. (2016). USP44 Is an Integral Component of N-CoR that Contributes to Gene Repression by Deubiquitinating Histone H2B. Cel Rep 17, 2382-2393. doi:10.1016/j.celrep.2016.10.076

Lee, B. H., Lee, M. J., Park, S., Oh, D. C., Elsasser, S., Chen, P. C., et al. (2010). Enhancement of Proteasome Activity by a Small-Molecule Inhibitor of USP14. Nature 467, 179-184. doi:10.1038/nature09299

Lee, H. J., Pham, T., Chang, M. T., Barnes, D., Cai, A. G., Noubade, R., et al. (2020). The Tumor Suppressor BAP1 Regulates the Hippo Pathway in Pancreatic Ductal Adenocarcinoma. Cancer Res. 80, 1656-1668. doi:10.1158/0008-5472. CAN-19-1704

Lee, J. G., Baek, K., Soetandyo, N., and Ye, Y. (2013). Reversible Inactivation of Deubiquitinases by Reactive Oxygen Species In Vitro and in Cells. Nat. Commun. 4, 1568. doi:10.1038/ncomms 2532

Leroy, E., Boyer, R., Auburger, G., Leube, B., Ulm, G., Mezey, E., et al. (1998). The Ubiquitin Pathway in Parkinson's Disease. Nature 395, 451-452. doi:10.1038/ 26652

Leznicki, P., and Kulathu, Y. (2017). Mechanisms of Regulation and Diversification of Deubiquitylating Enzyme Function. J. Cel Sci. 130, 1997-2006. doi:10.1242/ jcs. 201855

Li, H., and Seth, A. (2004). An RNF11: Smurf2 Complex Mediates Ubiquitination of the AMSH Protein. Oncogene 23, 1801-1808. doi:10. 1038/sj.onc. 1207319

Li, J., Tan, Q., Yan, M., Liu, L., Lin, H., Zhao, F., et al. (2014). miRNA-200c Inhibits Invasion and Metastasis of Human Non-small Cell Lung Cancer by Directly Targeting Ubiquitin Specific Peptidase 25. Mol. Cancer 13, 166. doi:10.1186/ 1476-4598-13-166

Li, Y., Luo, K., Yin, Y., Wu, C., Deng, M., Li, L., et al. (2017). USP13 Regulates the RAP80-BRCA1 Complex Dependent DNA Damage Response. Nat. Commun. 8, 15752. doi:10.1038/ncomms 15752

Li, Y., and Reverter, D. (2021). Molecular Mechanisms of DUBs Regulation in Signaling and Disease. Ijms 22, 986. doi:10.3390/ijms22030986

Li, Z., Wang, D., Na, X., Schoen, S. R., Messing, E. M., and Wu, G. (2002). Identification of a deubiquitinating enzyme subfamily as substrates of the von Hippel-Lindau tumor suppressor. Biochem. Biophys. Res. Commun. 294, 700-709. doi:10.1016/S0006-291X(02)00534-X

Lim, J., Hao, T., Shaw, C., Patel, A. J., Szabó, G., Rual, J. F., et al. (2006). A ProteinProtein Interaction Network for Human Inherited Ataxias and Disorders of Purkinje Cell Degeneration. Cell 125, 801-814. doi:10.1016/j.cell.2006.03.032

Lin, D., Zhang, M., Zhang, M. X., Ren, Y., Jin, J., Zhao, Q., et al. (2015). Induction of USP25 by Viral Infection Promotes Innate Antiviral Responses by Mediating the Stabilization of TRAF3 and TRAF6. Proc. Natl. Acad. Sci. USA 112, 11324-11329. doi:10.1073/pnas.1509968112

Lin, S. C., Chung, J. Y., Lamothe, B., Rajashankar, K., Lu, M., Lo, Y. C., et al. (2008). Molecular Basis for the Unique Deubiquitinating Activity of the NF-kappaB Inhibitor A20. J. Mol. Biol. 376, 526-540. doi:10.1016/j.jmb.2007.11.092
Liu, H., Zhang, H., Wang, X., Tian, Q., Hu, Z., Peng, C., et al. (2015a). The Deubiquitylating Enzyme USP4 Cooperates with CtIP in DNA DoubleStrand Break End Resection. Cel Rep 13, 93-107. doi:10.1016/j.celrep. 2015.08.056

Liu, S., Liu, X., Wang, H., Zhou, Q., Liang, Y., Sui, A., et al. (2015b). Lentiviral Vector-Mediated Doxycycline-Inducible USP39 shRNA or cDNA Expression in Triple-Negative Breast Cancer Cells. Oncol. Rep. 33, 2477-2483. doi:10.3892/ or.2015.3872

Liu, X., Li, H., Zhong, B., Blonska, M., Gorjestani, S., Yan, M., et al. (2013). USP18 Inhibits NF-Kb and NFAT Activation during Th17 Differentiation by Deubiquitinating the TAK1-TAB1 Complex. J. Exp. Med. 210, 1575-1590. doi:10.1084/jem.20122327

Liu, Z., Meray, R. K., Grammatopoulos, T. N., Fredenburg, R. A., Cookson, M. R., Liu, Y., et al. (2009). Membrane-associated Farnesylated UCH-L1 Promotes Alpha-Synuclein Neurotoxicity and Is a Therapeutic Target for Parkinson's Disease. Proc. Natl. Acad. Sci. U. S. A. 106, 4635-4640. doi:10.1073/pnas. 0806474106

LoGrasso, P. V., Hawkins, J., Frank, L. J., Wisniewski, D., and Marcy, A. (1996). Mechanism of Activation for Zap-70 Catalytic Activity. Proc. Natl. Acad. Sci. USA 93, 12165-12170. doi:10.1073/pnas.93.22.12165

Lopez-Castejon, G., and Edelmann, M. J. (2016). Deubiquitinases: Novel Therapeutic Targets in Immune Surveillance?. Mediators Inflamm. 2016, 3481371. doi:10.1155/2016/3481371

López-Otín, C., and Hunter, T. (2010). The Regulatory Crosstalk between Kinases and Proteases in Cancer. Nat. Rev. Cancer 10, 278-292. doi:10.1038/nrc2823

Lukas, C., Sørensen, C. S., Kramer, E., Santoni-Rugiu, E., Lindeneg, C., Peters, J. M., et al. (1999). Accumulation of Cyclin B1 Requires E2F and Cyclin-A-dependent Rearrangement of the Anaphase-Promoting Complex. Nature 401, 815-818. doi: $10.1038 / 44611$

Luo, K., Li, L., Li, Y., Wu, C., Yin, Y., Chen, Y., et al. (2016). A Phosphorylation-Deubiquitination cascade Regulates the BRCA2-RAD51 axis in Homologous Recombination. Genes Dev. 30, 2581-2595. doi:10. 1101/gad.289439.116

Madan, B., Walker, M. P., Young, R., Quick, L., Orgel, K. A., Ryan, M., et al. (2016). USP6 Oncogene Promotes Wnt Signaling by Deubiquitylating Frizzleds. Proc. Natl. Acad. Sci. U. S. A. 113, E2945-E2954. doi:10.1073/ pnas. 1605691113

Mader, J., Huber, J., Bonn, F., Dötsch, V., Rogov, V. V., and Bremm, A. (2020). Oxygen-dependent Asparagine Hydroxylation of the Ubiquitin-Associated (UBA) Domain in Cezanne Regulates Ubiquitin Binding. J. Biol. Chem. 295, 2160-2174. doi:10.1074/jbc.RA119.010315

Malakhov, M. P., Malakhova, O. A., Kim, K. I., Ritchie, K. J., and Zhang, D. E. (2002). UBP43 (USP18) Specifically Removes ISG15 from Conjugated Proteins. J. Biol. Chem. 277, 9976-9981. doi:10.1074/jbc.M109078200

Malakhova, O. A., Kim, K. I., Luo, J. K., Zou, W., Kumar, K. G., Fuchs, S. Y., et al. (2006). UBP43 Is a Novel Regulator of Interferon Signaling Independent of its ISG15 Isopeptidase Activity. Embo J. 25, 2358-2367. doi:10.1038/sj.emboj. 7601149

Mashtalir, N., Daou, S., Barbour, H., Sen, N. N., Gagnon, J., Hammond-Martel, I., et al. (2014). Autodeubiquitination Protects the Tumor Suppressor BAP1 from Cytoplasmic Sequestration Mediated by the Atypical Ubiquitin Ligase UBE2O. Mol. Cel 54, 392-406. doi:10.1016/j.molcel.2014.03.002

Masoumi, K. C., Marfany, G., Wu, Y., and Massoumi, R. (2016). Putative Role of SUMOylation in Controlling the Activity of Deubiquitinating Enzymes in Cancer. Future Oncol. 12, 565-574. doi:10.2217/fon.15.320

Massoumi, R. (2011). CYLD: a Deubiquitination Enzyme with Multiple Roles in Cancer. Future Oncol. 7, 285-297. doi:10.2217/fon.10.187

Matos, C. A., Nóbrega, C., Louros, S. R., Almeida, B., Ferreiro, E., Valero, J., et al. (2016). Ataxin-3 Phosphorylation Decreases Neuronal Defects in Spinocerebellar Ataxia Type 3 Models. J. Cel Biol. 212, 465-480. doi:10. $1083 /$ jcb. 201506025

Mayya, V., and Han, D. K. (2009). Phosphoproteomics by Mass Spectrometry: Insights, Implications, Applications and Limitations. Expert Rev. Proteomics 6, 605-618. doi:10.1586/epr.09.84

Mayya, V., Lundgren, D. H., Hwang, S. I., Rezaul, K., Wu, L., Eng, J. K., et al. (2009). Quantitative Phosphoproteomic Analysis of T Cell Receptor Signaling Reveals System-wide Modulation of Protein-Protein Interactions. Sci. Signal. 2, ra46. doi:10.1126/scisignal.2000007 
Mei, Y., Hahn, A. A., Hu, S., and Yang, X. (2011). The USP19 Deubiquitinase Regulates the Stability of C-IAP1 and C-IAP2. J. Biol. Chem. 286, 35380-35387. doi:10.1074/jbc.M111.282020

Meray, R. K., and Lansbury, P. T. (2007). Reversible Monoubiquitination Regulates the Parkinson Disease-Associated Ubiquitin Hydrolase UCH-L1. J. Biol. Chem. 282, 10567-10575. doi:10.1074/jbc.M611153200

Meulmeester, E., Kunze, M., Hsiao, H. H., Urlaub, H., and Melchior, F. (2008). Mechanism and Consequences for Paralog-specific SUMOylation of Ubiquitinspecific Protease 25. Mol. Cel 30, 610-619. doi:10.1016/j.molcel.2008.03.021

Mevissen, T. E., Hospenthal, M. K., Geurink, P. P., Elliott, P. R., Akutsu, M., Arnaudo, N., et al. (2013). OTU Deubiquitinases Reveal Mechanisms of Linkage Specificity and Enable Ubiquitin Chain Restriction Analysis. Cell 154, 169-184. doi:10.1016/j.cell.2013.05.046

Mevissen, T. E. T., and Komander, D. (2017). Mechanisms of Deubiquitinase Specificity and Regulation. Annu. Rev. Biochem. 86, 159-192. doi:10.1146/ annurev-biochem-061516-044916

Mines, M. A., Goodwin, J. S., Limbird, L. E., Cui, F. F., and Fan, G. H. (2009). Deubiquitination of CXCR4 by USP14 Is Critical for Both CXCL12-Induced CXCR4 Degradation and Chemotaxis but Not ERK Ativation. J. Biol. Chem. 284, 5742-5752. doi:10.1074/jbc.M808507200

Misaghi, S., Galardy, P. J., Meester, W. J., Ovaa, H., Ploegh, H. L., and Gaudet, R. (2005). Structure of the Ubiquitin Hydrolase UCH-L3 Complexed with a Suicide Substrate. J. Biol. Chem. 280, 1512-1520. doi:10.1074/jbc.M410770200

Mizuno, E., Kitamura, N., and Komada, M. (2007). 14-3-3-dependent Inhibition of the Deubiquitinating Activity of UBPY and its Cancellation in the M Phase. Exp. Cel Res. 313, 3624-3634. doi:10.1016/j.yexcr.2007.07.028

Mueller, T., Breuer, P., Schmitt, I., Walter, J., Evert, B. O., and Wüllner, U. (2009). CK2-dependent Phosphorylation Determines Cellular Localization and Stability of Ataxin-3. Hum. Mol. Genet. 18, 3334-3343. doi:10.1093/hmg/ ddp 274

Mukai, A., Mizuno, E., Kobayashi, K., Matsumoto, M., Nakayama, K. I., Kitamura, N., et al. (2008). Dynamic Regulation of Ubiquitylation and Deubiquitylation at the central Spindle during Cytokinesis. J. Cel Sci. 121, 1325-1333. doi:10.1242/ jcs. 027417

Murtaza, M., Jolly, L. A., Gecz, J., and Wood, S. A. (2015). La FAM Fatale: USP9X in Development and Disease. Cell Mol Life Sci 72, 2075-2089. doi:10.1007/ s00018-015-1851-0

Naik, E., and Dixit, V. M. (2016). Usp9X Is Required for Lymphocyte Activation and Homeostasis through its Control of ZAP70 Ubiquitination and PKC $\beta$ Kinase Activity. J. Immunol. 196, 3438-3451. doi:10.4049/jimmunol. 1403165

Naik, E., Webster, J. D., DeVoss, J., Liu, J., Suriben, R., and Dixit, V. M. (2014). Regulation of Proximal T Cell Receptor Signaling and Tolerance Induction by Deubiquitinase Usp9X. J. Exp. Med. 211, 1947-1955. doi:10.1084/jem.20140860

Nakamura, N., and Hirose, S. (2008). Regulation of Mitochondrial Morphology by USP30, a Deubiquitinating Enzyme Present in the Mitochondrial Outer Membrane. Mol. Biol. Cel 19, 1903-1911. doi:10.1091/mbc.E07-11-1103

Nakamura, T., Hillova, J., Mariage-Samson, R., Onno, M., Huebner, K., Cannizzaro, L. A., et al. (1992). A Novel Transcriptional Unit of the Tre Oncogene Widely Expressed in Human Cancer Cells. Oncogene 7, 733-741. PMID: 1565468.

Nayler, O., Stamm, S., and Ullrich, A. (1997). Characterization and Comparison of Four Serine- and Arginine-Rich (SR) Protein Kinases. Biochem. J. 326 ( Pt 3), 693-700. doi:10.1042/bj3260693

Ni, Y., Tao, L., Chen, C., Song, H., Li, Z., Gao, Y., et al. (2015). The Deubiquitinase USP17 Regulates the Stability and Nuclear Function of IL-33. Int. J. Mol. Sci. 16, 27956-27966. doi:10.3390/ijms161126063

Nijman, S. M., Luna-Vargas, M. P., Velds, A., Brummelkamp, T. R., Dirac, A. M., Sixma, T. K., et al. (2005). A Genomic and Functional Inventory of Deubiquitinating Enzymes. Cell 123, 773-786. doi:10.1016/j.cell.2005.11.007

Okino, Y., Machida, Y., Frankland-Searby, S., and Machida, Y. J. (2015). BRCA1associated Protein 1 (BAP1) Deubiquitinase Antagonizes the UbiquitinMediated Activation of FoxK2 Target Genes. J. Biol. Chem. 290, 1580-1591. doi:10.1074/jbc.M114.609834

Olazabal-Herrero, A., García-Santisteban, I., and Rodríguez, J. A. (2015). Structure-function Analysis of USP1: Insights into the Role of Ser313 Phosphorylation Site and the Effect of Cancer-Associated Mutations on Autocleavage. Mol. Cancer 14, 33. doi:10.1186/s12943-015-0311-7
Olsen, J. V., Vermeulen, M., Santamaria, A., Kumar, C., Miller, M. L., Jensen, L. J., et al. (2010). Quantitative Phosphoproteomics Reveals Widespread Full Phosphorylation Site Occupancy during Mitosis. Sci. Signal. 3 (104), ra3. doi:10.1126/scisignal.2000475

Olsten, M. E., and Litchfield, D. W. (2004). Order or Chaos? an Evaluation of the Regulation of Protein Kinase CK2. Biochem. Cel Biol. 82, 681-693. doi:10.1139/ o04-116

Osaka, H., Wang, Y. L., Takada, K., Takizawa, S., Setsuie, R., Li, H., et al. (2003). Ubiquitin Carboxy-Terminal Hydrolase L1 Binds to and Stabilizes Monoubiquitin in Neuron. Hum. Mol. Genet. 12, 1945-1958. doi:10.1093/ $\mathrm{hmg} / \mathrm{ddg} 211$

Pan, L., Chen, Z., Wang, L., Chen, C., Li, D., Wan, H., et al. (2014). Deubiquitination and Stabilization of T-Bet by USP10. Biochem. Biophys. Res. Commun. 449, 289-294. doi:10.1016/j.bbrc.2014.05.037

Pan, Z., Pan, H., Zhang, J., Yang, Y., Liu, H., Yang, Y., et al. (2015). Lentivirus Mediated Silencing of Ubiquitin Specific Peptidase 39 Inhibits Cell Proliferation of Human Hepatocellular Carcinoma Cells In Vitro. Biol. Res. 48, 18. doi:10. 1186/s40659-015-0006-y

Pareja, F., Ferraro, D. A., Rubin, C., Cohen-Dvashi, H., Zhang, F., Aulmann, S., et al. (2012). Deubiquitination of EGFR by Cezanne-1 Contributes to Cancer Progression. Oncogene 31, 4599-4608. doi:10.1038/onc.2011.587

Parsons, J. L., Dianova, I. I., Khoronenkova, S. V., Edelmann, M. J., Kessler, B. M., and Dianov, G. L. (2011). USP47 Is a Deubiquitylating Enzyme that Regulates Base Excision Repair by Controlling Steady-State Levels of DNA Polymerase $\beta$. Mol. Cel 41, 609-615. doi:10.1016/j.molcel.2011.02.016

Paudel, P., Zhang, Q., Leung, C., Greenberg, H. C., Guo, Y., Chern, Y. H., et al. (2019). Crystal Structure and Activity-Based Labeling Reveal the Mechanisms for Linkage-specific Substrate Recognition by Deubiquitinase USP9X. Proc. Natl. Acad. Sci. U. S. A. 116, 7288-7297. doi:10.1073/pnas.1815027116

Peschiaroli, A., Skaar, J. R., Pagano, M., and Melino, G. (2010). The Ubiquitinspecific Protease USP47 Is a Novel Beta-TrCP Interactor Regulating Cell Survival. Oncogene 29, 1384-1393. doi:10.1038/onc.2009.430

Pinto-Fernandez, A., and Kessler, B. M. (2016). DUBbing Cancer: Deubiquitylating Enzymes Involved in Epigenetics, DNA Damage and the Cell Cycle as Therapeutic Targets. Front. Genet. 7, 133. doi:10.3389/fgene.2016.00133

Pohl, C., and Jentsch, S. (2008). Final Stages of Cytokinesis and Midbody Ring Formation Are Controlled by BRUCE. Cell 132, 832-845. doi:10.1016/j.cell. 2008.01.012

Popov, N., Herold, S., Llamazares, M., Schülein, C., and Eilers, M. (2007a). Fbw7 and Usp28 Regulate Myc Protein Stability in Response to DNA Damage. Cell Cycle 6, 2327-2331. doi:10.4161/cc.6.19.4804

Popov, N., Wanzel, M., Madiredjo, M., Zhang, D., Beijersbergen, R., Bernards, R., et al. (2007b). The Ubiquitin-specific Protease USP28 Is Required for MYC Stability. Nat. Cel Biol. 9, 765-774. doi:10.1038/ncb1601

Poyton, R. O., Ball, K. A., and Castello, P. R. (2009). Mitochondrial Generation of Free Radicals and Hypoxic Signaling. Trends Endocrinol. Metab. 20, 332-340. doi:10.1016/j.tem.2009.04.001

Pozhidaeva, A., and Bezsonova, I. (2019). USP7: Structure, Substrate Specificity, and Inhibition. DNA Repair (Amst) 76, 30-39. doi:10.1016/j.dnarep.2019. 02.005

Reincke, M., Sbiera, S., Hayakawa, A., Theodoropoulou, M., Osswald, A., Beuschlein, F., et al. (2015). Mutations in the Deubiquitinase Gene USP8 Cause Cushing's Disease. Nat. Genet. 47, 31-38. doi:10.1038/ng.3166

Reyes-Turcu, F. E., Ventii, K. H., and Wilkinson, K. D. (2009). Regulation and Cellular Roles of Ubiquitin-specific Deubiquitinating Enzymes. Annu. Rev. Biochem. 78, 363-397. doi:10.1146/annurev.biochem.78.082307.091526

Ritorto, M. S., Ewan, R., Perez-Oliva, A. B., Knebel, A., Buhrlage, S. J., Wightman, M., et al. (2014). Screening of DUB Activity and Specificity by MALDI-TOF Mass Spectrometry. Nat. Commun. 5, 4763. doi:10.1038/ncomms5763

Row, P. E., Liu, H., Hayes, S., Welchman, R., Charalabous, P., Hofmann, K., et al. (2009). The MIT Domain of UBPY Constitutes a CHMP Binding and Endosomal Localization Signal Required for Efficient Epidermal Growth Factor Receptor Degradation. J. Biol. Chem. 282, 30929-30937. doi:10.1016/ S0021-9258(20)32532-110.1074/jbc.M704009200

Sahtoe, D. D., and Sixma, T. K. (2015). Layers of DUB Regulation. Trends Biochem. Sci. 40, 456-467. doi:10.1016/j.tibs.2015.05.002

Scaglione, K. M., Basrur, V., Ashraf, N. S., Konen, J. R., Elenitoba-Johnson, K. S., Todi, S. V., et al. (2013). The Ubiquitin-Conjugating Enzyme (E2) Ube2w 
Ubiquitinates the N Terminus of Substrates. J. Biol. Chem. 288, 18784-18788. doi:10.1074/jbc.C113.477596

Schaeffer, V., Akutsu, M., Olma, M. H., Gomes, L. C., Kawasaki, M., and Dikic, I. (2014). Binding of OTULIN to the PUB Domain of HOIP Controls NF-Kb Signaling. Mol. Cel 54, 349-361. doi:10.1016/j.molcel.2014.03.016

Schlicher, L., Wissler, M., Preiss, F., Brauns-Schubert, P., Jakob, C., Dumit, V., et al. (2016). SPATA2 Promotes CYLD Activity and Regulates TNF-Induced NF-Kb Signaling and Cell Death. EMBO Rep. 17, 1485-1497. doi:10.15252/embr. 201642592

Schoenfeld, A. R., Apgar, S., Dolios, G., Wang, R., and Aaronson, S. A. (2004). BRCA2 Is Ubiquitinated In Vivo and Interacts with USP11, a Deubiquitinating Enzyme that Exhibits Prosurvival Function in the Cellular Response to DNA Damage. Mol. Cel. Biol. 24, 7444-7455. doi:10.1128/MCB.24.17.7444-7455. 2004

Schofield, C. J., and Ratcliffe, P. J. (2004). Oxygen Sensing by HIF Hydroxylases. Nat. Rev. Mol. Cel Biol. 5, 343-354. doi:10.1038/nrm1366

Scholz, C. C., Cavadas, M. A., Tambuwala, M. M., Hams, E., Rodríguez, J., von Kriegsheim, A., et al. (2013). Regulation of IL-1 $\beta$-induced NF-Kb by Hydroxylases Links Key Hypoxic and Inflammatory Signaling Pathways. Proc. Natl. Acad. Sci. U. S. A. 110, 18490-18495. doi:10.1073/pnas. 1309718110

Scholz, C. C., Rodriguez, J., Pickel, C., Burr, S., Fabrizio, J. A., Nolan, K. A., et al. (2016). FIH Regulates Cellular Metabolism through Hydroxylation of the Deubiquitinase OTUB1. PLOS Biol. 14 (1), e1002347. doi:10.1371/journal. pbio. 1002347

Schulz, S., Chachami, G., Kozaczkiewicz, L., Winter, U., Stankovic-Valentin, N., Haas, P., et al. (2012). Ubiquitin-specific Protease-like 1 (USPL1) Is a SUMO Isopeptidase with Essential, Non-catalytic Functions. EMBO Rep. 13, 930-938. doi:10.1038/embor.2012.125

Scortegagna, M., Subtil, T., Qi, J., Kim, H., Zhao, W., Gu, W., et al. (2011). USP13 Enzyme Regulates Siah2 Ligase Stability and Activity via Noncatalytic Ubiquitin-Binding Domains. J. Biol. Chem. 286, 27333-27341. doi:10.1074/ jbc.M111.218214

Seki, T., Gong, L., Williams, A. J., Sakai, N., Todi, S. V., and Paulson, H. L. (2013). JosD1, a Membrane-Targeted Deubiquitinating Enzyme, Is Activated by Ubiquitination and Regulates Membrane Dynamics, Cell Motility, and Endocytosis. J. Biol. Chem. 288, 17145-17155. doi:10.1074/jbc.M113.463406

Semenza, G. L. (2009). Regulation of Oxygen Homeostasis by Hypoxia-Inducible Factor 1. Physiology (Bethesda) 24, 97-106. doi:10.1152/physiol.00045.2008

Shen, C., Ye, Y., Robertson, S. E., Lau, A. W., Mak, D. O., and Chou, M. M. (2005a). Calcium/calmodulin Regulates Ubiquitination of the Ubiquitin-specific Protease TRE17/USP6. J. Biol. Chem. 280, 35967-35973. doi:10.1074/jbc. M505220200

Shen, L., Tang, J. G., Tang, B. S., Jiang, H., Zhao, G. H., Xia, K., et al. (2005b). Research on Screening and Identification of Proteins Interacting with Ataxin-3. Zhonghua Yi Xue Yi Chuan Xue Za Zhi 22, 242-247. PMID: 15952105.

Sobhian, B., Shao, G., Lilli, D. R., Culhane, A. C., Moreau, L. A., Xia, B., et al. (2007). RAP80 Targets BRCA1 to Specific Ubiquitin Structures at DNA Damage Sites. Science 316, 1198-1202. doi:10.1126/science. 1139516

Song, H. Y., Rothe, M., and Goeddel, D. V. (1996). The Tumor Necrosis FactorInducible Zinc finger Protein A20 Interacts with TRAF1/TRAF2 and Inhibits NF-kappaB Activation. Proc. Natl. Acad. Sci. USA 93, 6721-6725. doi:10.1073/ pnas.93.13.6721

Song, J., Durrin, L. K., Wilkinson, T. A., Krontiris, T. G., and Chen, Y. (2004). Identification of a SUMO-Binding Motif that Recognizes SUMO-Modified Proteins. Proc. Natl. Acad. Sci. U. S. A. 101, 14373-14378. doi:10.1073/pnas. 0403498101

Sowa, M. E., Bennett, E. J., Gygi, S. P., and Harper, J. W. (2009). Defining the Human Deubiquitinating Enzyme Interaction Landscape. Cell 138, 389-403. doi:10.1016/j.cell.2009.04.042

Stevanin, G., Cassa, E., Cancel, G., Abbas, N., Dürr, A., Jardim, E., et al. (1995). Characterisation of the Unstable Expanded CAG Repeat in the MJD1 Gene in Four Brazilian Families of Portuguese Descent with Machado-Joseph Disease. J. Med. Genet. 32, 827-830. doi:10.1136/jmg.32.10.827

Sun, X. X., He, X., Yin, L., Komada, M., Sears, R. C., and Dai, M. S. (2015). The Nucleolar Ubiquitin-specific Protease USP36 Deubiquitinates and Stabilizes C-Myc. Proc. Natl. Acad. Sci. U. S. A. 112, 3734-3739. doi:10.1073/pnas. 1411713112
Suresh, B., Ramakrishna, S., Lee, H. J., Choi, J. H., Kim, J. Y., Ahn, W. S., et al. (2010). K48- and K63-Linked Polyubiquitination of Deubiquitinating Enzyme USP44. Cell Biol. Int. 34, 799-808. doi:10.1042/CBI20090144

Tam, S., Geller, R., Spiess, C., and Frydman, J. (2006). The Chaperonin TRiC Controls Polyglutamine Aggregation and Toxicity through Subunit-specific Interactions. Nat. Cel Biol. 8, 1155-1162. doi:10.1038/ncb1477

Taylor, S. S., and Kornev, A. P. (2011). Protein Kinases: Evolution of Dynamic Regulatory Proteins. Trends Biochem. Sci. 36, 65-77. doi:10.1016/j.tibs.2010. 09.006

Todi, S. V., and Paulson, H. L. (2011). Balancing Act: Deubiquitinating Enzymes in the Nervous System. Trends Neurosci. 34, 370-382. doi:10.1016/j.tins.2011. 05.004

Todi, S. V., Scaglione, K. M., Blount, J. R., Basrur, V., Conlon, K. P., Pastore, A., et al. (2010). Activity and Cellular Functions of the Deubiquitinating Enzyme and Polyglutamine Disease Protein Ataxin-3 Are Regulated by Ubiquitination at Lysine 117. J. Biol. Chem. 285, 39303-39313. doi:10.1074/ jbc.M110.181610

Todi, S. V., Winborn, B. J., Scaglione, K. M., Blount, J. R., Travis, S. M., and Paulson, H. L. (2009). Ubiquitination Directly Enhances Activity of the Deubiquitinating Enzyme Ataxin-3. EMBO J. 28, 372-382. doi:10.1038/ emboj.2008.289

Trompouki, E., Hatzivassiliou, E., Tsichritzis, T., Farmer, H., Ashworth, A., and Mosialos, G. (2003). CYLD Is a Deubiquitinating Enzyme that Negatively Regulates NF-kappaB Activation by TNFR Family Members. Nature 424, 793-796. doi:10.1038/nature01803

Turnbull, A. P., Ioannidis, S., Krajewski, W. W., Pinto-Fernandez, A., Heride, C., Martin, A. C. L., et al. (2017). Molecular Basis of USP7 Inhibition by Selective Small-Molecule Inhibitors. Nature 550, 481-486. doi:10.1038/ nature24451

Uras, I. Z., List, T., and Nijman, S. M. (2012). Ubiquitin-specific Protease 4 Inhibits Mono-Ubiquitination of the Master Growth Factor Signaling Kinase PDK1. PLOS ONE 7, e31003. doi:10.1371/journal.pone.0031003

Urbé, S., Liu, H., Hayes, S. D., Heride, C., Rigden, D. J., and Clague, M. J. (2012). Systematic Survey of Deubiquitinase Localization Identifies USP21 as a Regulator of Centrosome- and Microtubule-Associated Functions. Mol. Biol. Cel 23, 1095-1103. doi:10.1091/mbc.E11-08-0668

Valero, R., Bayés, M., Francisca Sánchez-Font, M., González-Angulo, O., GonzàlezDuarte, R., and Marfany, G. (2001). Characterization of Alternatively Spliced Products and Tissue-specific Isoforms of USP28 and USP25. Genome Biol. 2, RESEARCH0043. doi:10.1186/gb-2001-2-10-research0043

Van Damme, P., Lasa, M., Polevoda, B., Gazquez, C., Elosegui-Artola, A., Kim, D. S., et al. (2012). N-terminal Acetylome Analyses and Functional Insights of the N-Terminal Acetyltransferase NatB. Proc. Natl. Acad. Sci. U. S. A. 109, 12449-12454. doi:10.1073/pnas.1210303109

Villamil, M. A., Liang, Q., Chen, J., Choi, Y. S., Hou, S., Lee, K. H., et al. (2012). Serine Phosphorylation Is Critical for the Activation of Ubiquitin-specific Protease 1 and its Interaction with WD40-Repeat Protein UAF1. Biochemistry 51, 9112-9123. doi:10.1021/bi300845s

Visconti, R., Palazzo, L., Della Monica, R., and Grieco, D. (2012). Fcp1-dependent Dephosphorylation Is Required for M-Phase-Promoting Factor Inactivation at Mitosis Exit. Nat. Commun. 3, 894. doi:10.1038/ncomms 1886

Wada, K., and Kamitani, T. (2006). UnpEL/Usp4 Is Ubiquitinated by Ro52 and Deubiquitinated by Itself. Biochem. Biophys. Res. Commun. 342, 253-258. doi:10.1016/j.bbrc.2006.01.144

Wada, K., Tanji, K., and Kamitani, T. (2006). Oncogenic Protein UnpEL/Usp4 Deubiquitinates Ro52 by its Isopeptidase Activity. Biochem. Biophys. Res. Commun. 339, 731-736. doi:10.1016/j.bbrc.2005.11.076

Wang, L., Chen, Y. J., Xu, K., Wang, Y. Y., Shen, X. Z., and Tu, R. Q. (2014). High Expression of UCH37 Is Significantly Associated with Poor Prognosis in Human Epithelial Ovarian Cancer. Tumour Biol. 35, 11427-11433. doi:10. 1007/s13277-014-2446-3

Wang, L., Zhao, W., Zhang, M., Wang, P., Zhao, K., Zhao, X., et al. (2013). USP4 Positively Regulates RIG-I-Mediated Antiviral Response through Deubiquitination and Stabilization of RIG-I. J. Virol. 87, 4507-4515. doi:10. 1128/JVI.00031-13

Wang, W., Huang, X., Xin, H. B., Fu, M., Xue, A., and Wu, Z. H. (2015a). TRAF Family Member-Associated NF-Kb Activator (TANK) Inhibits Genotoxic Nuclear Factor $\mathrm{KB}$ Activation by Facilitating Deubiquitinase USP10- 
dependent Deubiquitination of TRAF6 Ligase. J. Biol. Chem. 290, 13372-13385. doi:10.1074/jbc.M115.643767

Wang, W., Li, M., Ponnusamy, S., Chi, Y., Xue, J., Fahmy, B., et al. (2020a). ABL1dependent OTULIN Phosphorylation Promotes Genotoxic Wnt/ $\beta$-Catenin Activation to Enhance Drug Resistance in Breast Cancers. Nat. Commun. 11, 3965. doi:10.1038/s41467-020-17770-9

Wang, W., and Wu, Z. H. (2020). OTULIN Couples WNT Signaling to Resistance in Triple-Negative Breast Cancer. Mol. Cel. Oncol. 7, 1825904. doi:10.1080/ 23723556.2020.1825904

Wang, Y., Jiang, Y., Ding, S., Li, J., Song, N., Ren, Y., et al. (2018). Small Molecule Inhibitors Reveal Allosteric Regulation of USP14 via Steric Blockade. Cel Res 28, 1186-1194. doi:10.1038/s41422-018-0091-x

Wang, Y., Wang, J., Zhong, J., Deng, Y., Xi, Q., He, S., et al. (2015b). Ubiquitinspecific Protease 14 (USP14) Regulates Cellular Proliferation and Apoptosis in Epithelial Ovarian Cancer. Med. Oncol. 32, 379. doi:10.1007/s12032-0140379-8

Wang, Y., Zhou, L., Lu, J., Jiang, B., Liu, C., and Guo, J. (2020b). USP4 Function and Multifaceted Roles in Cancer: a Possible and Potential Therapeutic Target. Cancer Cel Int 20, 298. doi:10.1186/s12935-020-01391-9

Weishäupl, D., Schneider, J., Peixoto Pinheiro, B., Ruess, C., Dold, S. M., von Zweydorf, F., et al. (2019). Physiological and Pathophysiological Characteristics of Ataxin-3 Isoforms. J. Biol. Chem. 294, 644-661. doi:10.1074/jbc.RA118. 005801

Wen, D., Xu, Z., Xia, L., Liu, X., Tu, Y., Lei, H., et al. (2014). Important Role of SUMOylation of Spliceosome Factors in Prostate Cancer Cells. J. Proteome Res. 13, 3571-3582. doi:10.1021/pr4012848

Wertz, I. E., Newton, K., Seshasayee, D., Kusam, S., Lam, C., Zhang, J., et al. (2015). Phosphorylation and Linear Ubiquitin Direct A20 Inhibition of Inflammation. Nature 528, 370-375. doi:10.1038/nature16165

Wijnhoven, P., Konietzny, R., Blackford, A. N., Travers, J., Kessler, B. M., Nishi, R., et al. (2015). USP4 Auto-Deubiquitylation Promotes Homologous Recombination. Mol. Cel 60, 362-373. doi:10.1016/j.molcel.2015.09.019

Wilkinson, K. A., and Henley, J. M. (2010). Mechanisms, Regulation and Consequences of Protein SUMOylation. Biochem. J. 428, 133-145. doi:10. 1042/BJ20100158

Wilson, S. M., Bhattacharyya, B., Rachel, R. A., Coppola, V., Tessarollo, L., Householder, D. B., et al. (2002). Synaptic Defects in Ataxia Mice Result from a Mutation in Usp14, Encoding a Ubiquitin-specific Protease. Nat. Genet. 32, 420-425. doi:10.1038/ng1006

Wiltshire, T. D., Lovejoy, C. A., Wang, T., Xia, F., O'Connor, M. J., and Cortez, D. (2010). Sensitivity to poly(ADP-Ribose) Polymerase (PARP) Inhibition Identifies Ubiquitin-specific Peptidase 11 (USP11) as a Regulator of DNA Double-Strand Break Repair. J. Biol. Chem. 285, 14565-14571. doi:10.1074/jbc. M110.104745

Wu, N., Liu, C., Bai, C., Han, Y. P., Cho, W. C., and Li, Q. (2013). Over-expression of Deubiquitinating Enzyme USP14 in Lung Adenocarcinoma Promotes Proliferation through the Accumulation of $\beta$-catenin. Int. J. Mol. Sci. 14, 10749-10760. doi:10.3390/ijms140610749

Xu, D., Shan, B., Lee, B. H., Zhu, K., Zhang, T., Sun, H., et al. (2015). Phosphorylation and Activation of Ubiquitin-specific Protease-14 by Akt Regulates the UbiquitinProteasome System. eLife 4, e10510. doi:10.7554/eLife.10510

Xu, X., Kalac, M., Markson, M., Chan, M., Brody, J. D., Bhagat, G., et al. (2020). Reversal of CYLD Phosphorylation as a Novel Therapeutic Approach for Adult T-Cell Leukemia/lymphoma (ATLL). Cel Death Dis 11, 94. doi:10.1038/s41419020-2294-6

Xu, Z., Pei, L., Wang, L., Zhang, F., Hu, X., and Gui, Y. (2014). Snail1-dependent Transcriptional Repression of Cezanne2 in Hepatocellular Carcinoma. Oncogene 33, 2836-2845. doi:10.1038/onc.2013.243

Yuan, J., Luo, K., Zhang, L., Cheville, J. C., and Lou, Z. (2010). USP10 Regulates P53 Localization and Stability by Deubiquitinating P53. Cell 140, 384-396. doi:10. 1016/j.cell.2009.12.032

Yuan, L., Lv, Y., Li, H., Gao, H., Song, S., Zhang, Y., et al. (2015). Deubiquitylase OTUD3 Regulates PTEN Stability and Suppresses Tumorigenesis. Nat. Cel Biol. 17, 1169-1181. doi:10.1038/ncb3218

Zeng, C., Zhao, C., Ge, F., Li, Y., Cao, J., Ying, M., et al. (2020). Machado-Joseph Deubiquitinases: from Cellular Functions to Potential Therapy Targets. Front. Pharmacol. 11, 1311. doi:10.3389/fphar.2020.01311
Zeng, W. F., Navaratne, K., Prayson, R. A., and Weil, R. J. (2007). Aurora B Expression Correlates with Aggressive Behaviour in Glioblastoma Multiforme. J. Clin. Pathol. 60, 218-221. doi:10.1136/jcp.2006.036806

Zhang, D., Zaugg, K., Mak, T. W., and Elledge, S. J. (2006). A Role for the Deubiquitinating Enzyme USP28 in Control of the DNA-Damage Response. Cell 126, 529-542. doi:10.1016/j.cell.2006.06.039

Zhang, J., Zhang, X., Xie, F., Zhang, Z., van Dam, H., Zhang, L., et al. (2014). The Regulation of TGF- $\beta /$ SMAD Signaling by Protein Deubiquitination. Protein Cell 5, 503-517. doi:10.1007/s13238-014-0058-8

Zhang, L., Liu, J., Qian, L., Feng, Q., Wang, X., Yuan, Y., et al. (2018). Induction of OTUD1 by RNA Viruses Potently Inhibits Innate Immune Responses by Promoting Degradation of the MAVS/TRAF3/TRAF6 Signalosome. PLOS Pathog. 14, e1007067. doi:10.1371/journal.ppat.1007067

Zhang, L., Xu, B., Qiang, Y., Huang, H., Wang, C., Li, D., et al. (2015a). Overexpression of Deubiquitinating Enzyme USP28 Promoted Non-small Cell Lung Cancer Growth. J. Cel. Mol. Med. 19, 799-805. doi:10.1111/jcmm. 12426

Zhang, L., Zhou, F., Drabsch, Y., Gao, R., Snaar-Jagalska, B. E., Mickanin, C., et al. (2012). USP4 Is Regulated by AKT Phosphorylation and Directly Deubiquitylates TGF- $\beta$ Type I Receptor. Nat. Cel Biol. 14, 717-726. doi:10. 1038/ncb2522

Zhang, Y., You, J., Wang, X., and Weber, J. (2015b). The DHX33 RNA Helicase Promotes mRNA Translation Initiation. Mol. Cel. Biol. 35, 2918-2931. doi:10. 1128/MCB.00315-15

Zhang, Z., Jones, A., Joo, H. Y., Zhou, D., Cao, Y., Chen, S., et al. (2013). USP49 Deubiquitinates Histone H2B and Regulates Cotranscriptional Pre-mRNA Splicing. Genes Dev. 27, 1581-1595. doi:10.1101/gad.211037.112

Zhao, W., Steinfeld, J. B., Liang, F., Chen, X., Maranon, D. G., Jian Ma, C., et al. (2017). BRCA1-BARD1 Promotes RAD51-Mediated Homologous DNA Pairing. Nature 550, 360-365. doi:10.1038/nature24060

Zhao, Y., Majid, M. C., Soll, J. M., Brickner, J. R., Dango, S., and Mosammaparast, N. (2015). Noncanonical Regulation of Alkylation Damage Resistance by the OTUD4 Deubiquitinase. EMBO J. 34, 1687-1703. doi:10.15252/embj. 201490497

Zhao, Y., Mudge, M. C., Soll, J. M., Rodrigues, R. B., Byrum, A. K., Schwarzkopf, E. A., et al. (2018). OTUD4 Is a Phospho-Activated K63 Deubiquitinase that Regulates MyD88-dependent Signaling. Mol. Cel 69, 505. e5+. doi:10.1016/j. molcel.2018.01.009

Zhen, Y., Knobel, P. A., Stracker, T. H., and Reverter, D. (2014). Regulation of USP28 Deubiquitinating Activity by SUMO Conjugation. J. Biol. Chem. 289, 34838-34850. doi:10.1074/jbc.M114.601849

Zhong, B., Liu, X., Wang, X., Chang, S. H., Liu, X., Wang, A., et al. (2012). Negative Regulation of IL-17-mediated Signaling and Inflammation by the Ubiquitin-specific Protease USP25. Nat. Immunol. 13, 1110-1117. doi:10. 1038/ni.2427

Zhou, H., Di Palma, S., Preisinger, C., Peng, M., Polat, A. N., Heck, A. J., et al. (2013a). Toward a Comprehensive Characterization of a Human Cancer Cell Phosphoproteome. J. Proteome Res. 12, 260-271. doi:10.1021/ pr300630k

Zhou, Q., Lin, M., Feng, X., Ma, F., Zhu, Y., Liu, X., et al. (2020). Targeting CLK3 Inhibits the Progression of Cholangiocarcinoma by Reprogramming Nucleotide Metabolism. J. Exp. Med. 217. doi:10.1084/jem.20191779

Zhou, Y. F., Liao, S. S., Luo, Y. Y., Tang, J. G., Wang, J. L., Lei, L. F., et al. (2013b). SUMO-1 Modification on K166 of PolyQ-Expanded Ataxin-3 Strengthens its Stability and Increases its Cytotoxicity. PLOS ONE 8, e54214. doi:10.1371/ journal.pone.0054214

Conflict of Interest: The authors declare that the research was conducted in the absence of any commercial or financial relationships that could be construed as a potential conflict of interest.

Copyright (c) 2021 Wang and Wang. This is an open-access article distributed under the terms of the Creative Commons Attribution License (CC BY). The use, distribution or reproduction in other forums is permitted, provided the original author(s) and the copyright owner(s) are credited and that the original publication in this journal is cited, in accordance with accepted academic practice. No use, distribution or reproduction is permitted which does not comply with these terms. 